\title{
The Impact of Observed Deforestation on the Mesoscale Distribution of Rainfall and Clouds in Amazonia
}

\author{
JingFeng Wang, RAfael L. Bras, And Elfatih A. B. Eltahir \\ Department of Civil and Environmental Engineering, Massachusetts Institute of Technology, \\ Cambridge, Massachusetts
}

(Manuscript received 23 March 1999, in final form 15 February 2000)

\begin{abstract}
A numerical mesoscale model has been used to investigate the impact of mesoscale circulations on the distribution of precipitation and cloudiness over a deforested area in Amazonia. Observed patterns of deforestation in Rondônia, Amazonia, with scales on the order of $10 \mathrm{~km}$ were used in this study to describe land surface conditions. Various simulations have been performed to identify the conditions under which the mesoscale circulations induced by the heterogeneous land surface could enhance cloudiness and local rainfall. The simulation results suggest that the synoptic forcing, in terms of atmospheric stability and background horizontal wind, dominates during the rainy season; synoptic conditions were so favorable to moist convection that the added effect of surface heterogeneity was negligible. During the dry season, a noticeable impact of mesoscale circulations resulting in enhancement of shallow clouds was simulated; the mesoscale circulations also triggered scattered deep convection that altered the spatial distribution of precipitation. During the break period, the transition from the rainy season to the dry season, the impact of mesoscale circulations on low-level clouds was evident only after reducing the magnitude of the background wind.
\end{abstract}

\section{Introduction}

The impact of deforestation on climate is dependent on the scales of the deforested area. Previous analytical studies (e.g., Eltahir 1996) illustrate how large-scale deforestation $(\sim 2500 \mathrm{~km})$ could lead to reduction in rainfall and weakening of large-scale circulation. This effect is consistent with the results of several GCM studies that focused on the response of the tropical atmosphere to clearing of the entire Amazon rain forest (Dickinson and Henderson-Sellers 1988; Lean and Warrilow 1989; Nobre et al. 1991; and Dickinson and Kennedy 1992). Deforestation at smaller scales $(\sim 250 \mathrm{~km})$ may reduce local rainfall but may not affect the large-scale circulations. This result was confirmed by the modeling study of Eltahir and Bras (1994), which investigated the climate impact of deforestation in the Amazon over a limited region. At even smaller scales $(\sim 25 \mathrm{~km})$ deforestation is expected to trigger mesoscale circulations with rising motion over deforested areas. The potential impact of these circulations on rainfall and cloudiness is the subject of this paper.

The expanding deforestation over the Amazon basin

Corresponding author address: Jingfeng Wang, MIT, Room 48336, 15 Vassar Street, Cambridge, MA 02139.

E-mail: jfwang@mit.edu has created increasing land surface heterogeneity with much more complexity than that assumed in most numerical studies. Field observations have described patterns of intense change in land cover including the wellknown "fish-bone" patterns in Rondônia, Amazonia (e.g., Skole and Tucker 1993). The deforested areas could extend up to about $10^{3} \mathrm{~km}^{2}$, consisting of smaller patches with a length scale of tens of kilometers. Remote sensing observations indicate a significant upward trend in cloudiness over the deforested areas (Cutrim et al. 1995). A similar pattern has been observed in a midlatitude region (e.g., Rabin et al. 1990). It has been argued that the observed enhancement of convection at the mesoscale results from the mesoscale circulations induced by heterogeneity in the land surface. The objective of this study is to explore the physical link (if any) that connects the patterns of cloudiness to those of land cover and to identify the conditions under which mesoscale circulations induced by land surface heterogeneity may modify the distribution of clouds and local rainfall.

\section{Background}

Previous studies have pointed out the potential of significant mesoscale circulation over heterogeneous and surface. Linear analytical models have been used 


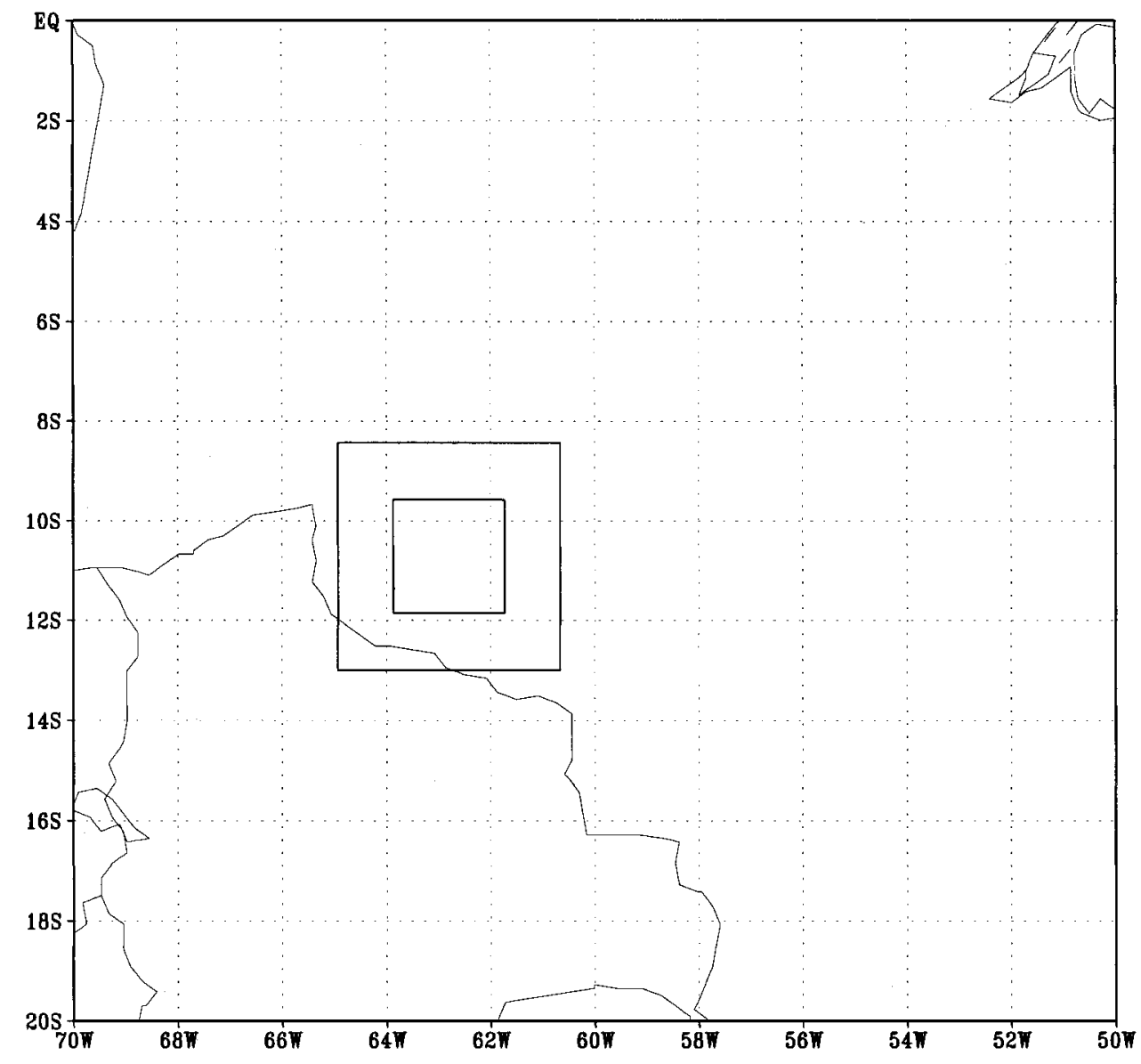

FIG. 1. Location of the nested simulation domains.

to investigate the fundamental behavior of the mesoscale circulations associated with idealized land surface patterns in a dry atmosphere. Rotunno (1983) derived a two-dimensional analytical solution of the mesoscale circulation driven by the diurnal cycle of differential heating associated with the land-sea contrast. Dalu and Pielke (1989, 1993) and Dalu et al. (1991) extended Rotunno's work to study the effect of nonperiodic surface forcing on the mesoscale circulation. They found that the vertical heat flux generated by the mesoscale circulation is of the same order as the diabatic sensible heat flux. Nonlinear mesoscale circulations have also been studied using numerical models. A number of twoand three-dimensional simulations have been performed to study the mesoscale circulation, in dry and moist atmospheres, over land surfaces with regular patterns of heterogeneity (Pielke 1974; Segal et al. 1989; Avissar and Pielke 1989; Avissar and Chen 1993; among others). These numerical studies suggested that significant flow, comparable to that of the sea-breeze case, can be induced when the land surface is covered by warm-cool stripes or patches of a range of sizes $\left(\sim 10^{1}-10^{2} \mathrm{~km}\right)$. Lynn et al. (1995) further argued that it was important to parameterize these circulations and to represent them within global circulation models.

Wang et al. (1996) developed a stochastic linear theory of three-dimensional mesoscale circulation, in a dry atmosphere, forced by complex land surface heterogeneity. In contrast to the earlier studies, the variable sensible heat flux over the surface was described by a two-dimensional homogeneous random field. An analytical solution was derived for momentum and heat flux as functions of stability, synoptic wind, and the parameters that characterize the complex land surface, that is, variance and length scale of the surface sensible heat flux. The dependence of the mesoscale circulation on the variability and length scale of the variable surface heating has been defined explicitly by this analytical solution.

The linear theory of Wang et al. (1996) predicts that stable stratification strongly inhibits the development of the mesoscale circulation and hence drastically reduces mesoscale transport of momentum, heat, and moisture. Mesoscale fluxes, in the linear analysis, are important only in an environment of neutral stratification and weak synoptic wind. The intensity of the mesoscale circula- 
(a)

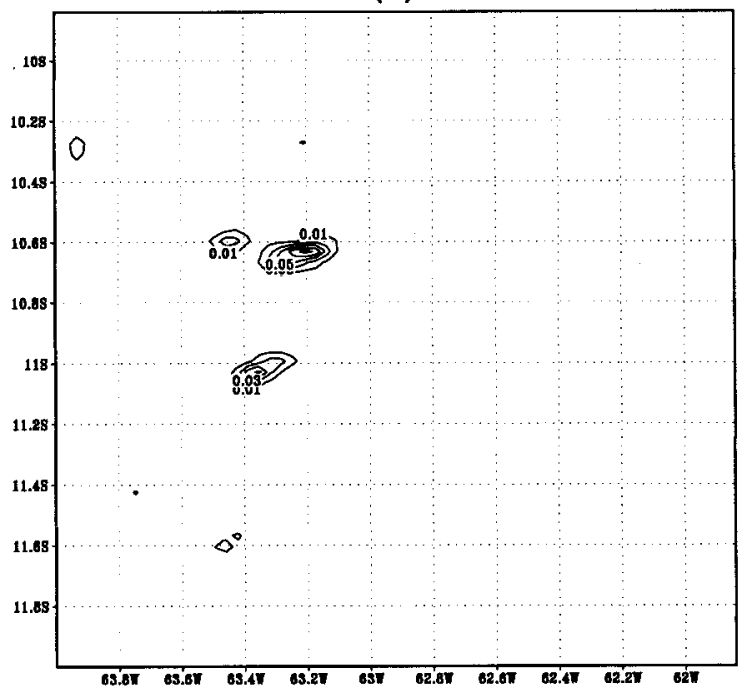

(b)

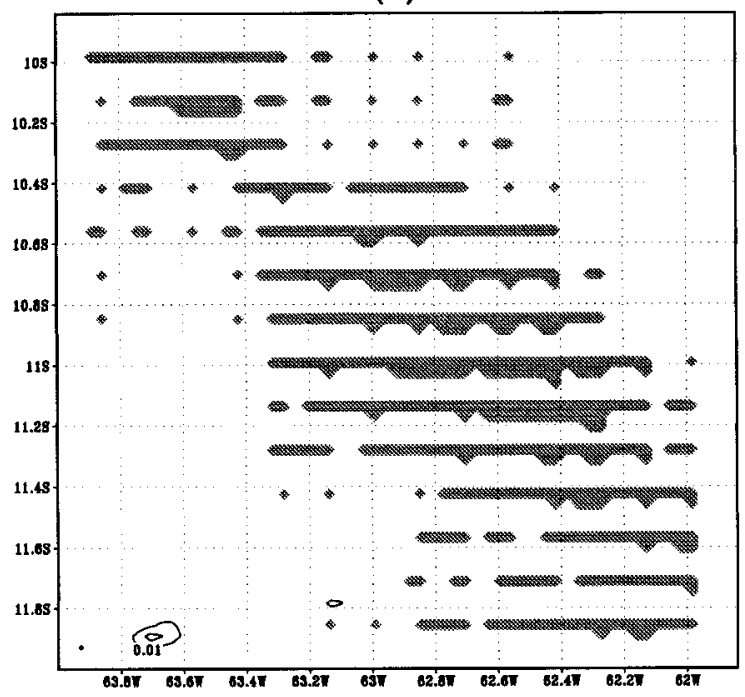

FIG. 2. Seventy-two-hour cumulative rainfall $(\mathrm{cm})$ for $(\mathrm{a})$ the control run and (b) the deforestation run. Break-period simulation (3-6 Nov 1990).

tion is shown to be proportional to the standard deviation of the turbulent sensible heat flux at the surface. In the lower atmosphere, the thermal variability of the landscape at the smaller length scales is more efficient in triggering dry convection, and, at higher altitudes, the atmospheric dynamics are more sensitive to thermal forcing at longer length scales. The atmosphere from bottom to top behaves as a low-pass filter to the thermal variability of the landscape.

Wang et al. (1998) investigated the nonlinear mesoscale circulation forced by complex land surface heterogeneity. This study further evaluated the dependence of the mesoscale circulation on the length scale of the

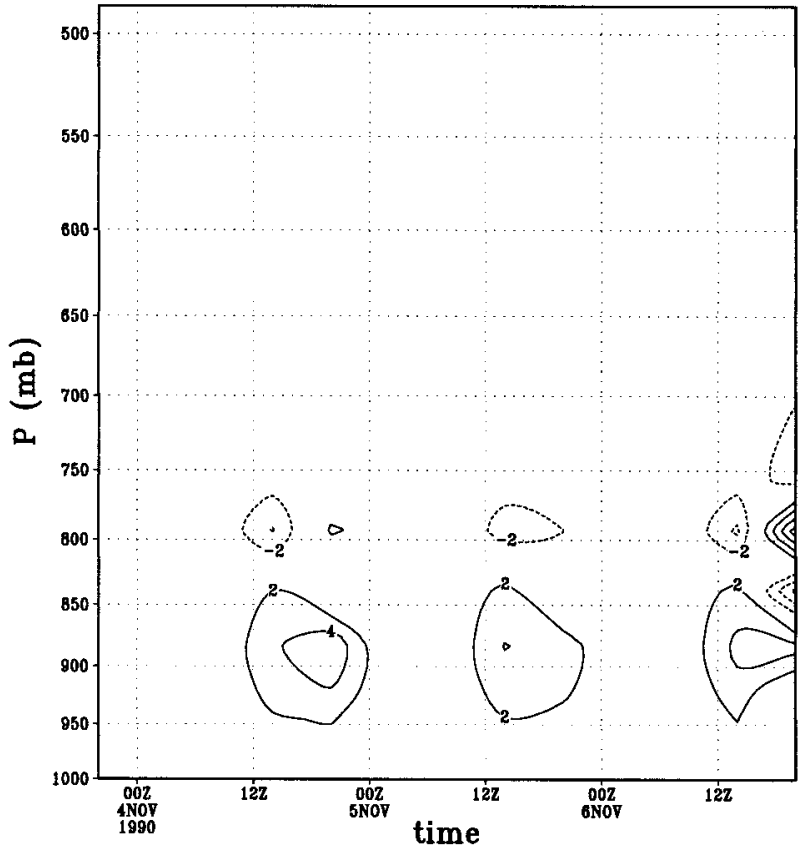

FIG. 3. Mesoscale heat flux $\left(\mathrm{W} \mathrm{m}^{-2}\right)$ caused by the variable land cover. Break-period simulation.

land surface heterogeneity by characterizing the variable land surface with different spectral distribution functions. The relative importance of the atmospheric stability and synoptic wind to the mesoscale circulation was also investigated. In general, the numerical solutions of nonlinear mesoscale circulation show qualitative agreement with those from the linear analytical theory. The stability of the atmosphere was identified as the dominant hurdle to the forcing of mesoscale circulations by land surfaces with random heterogeneity. The mesoscale circulation could reach $5-\mathrm{km}$ height in an atmosphere with neutral stratification but was suppressed down to a layer not deeper than 200 m near the surface in a stable atmosphere. When the near-surface (boundary) layer is neutral and the atmosphere above is stable, the mesoscale circulation is confined within the lowest $2-\mathrm{km}$ layer. It was concluded that stability strongly inhibits the development of dry convection. Nonlinear numerical simulations also suggest that the synoptic wind plays a secondary role in the development of mesoscale circulations. The inhibition by the synoptic wind was not as strong as predicted by the linear theory, which is consistent with the results of other numerical studies. The results of Wang et al. (1998) indicate that land surface heterogeneity with length scales near a few tens of kilometers is effective in forcing mesoscale circulations. The form of the distributions of the surface heterogeneity is not critical as long as it is characterized with similar variability and length scale.

There are two major limitations in the linear and non- 


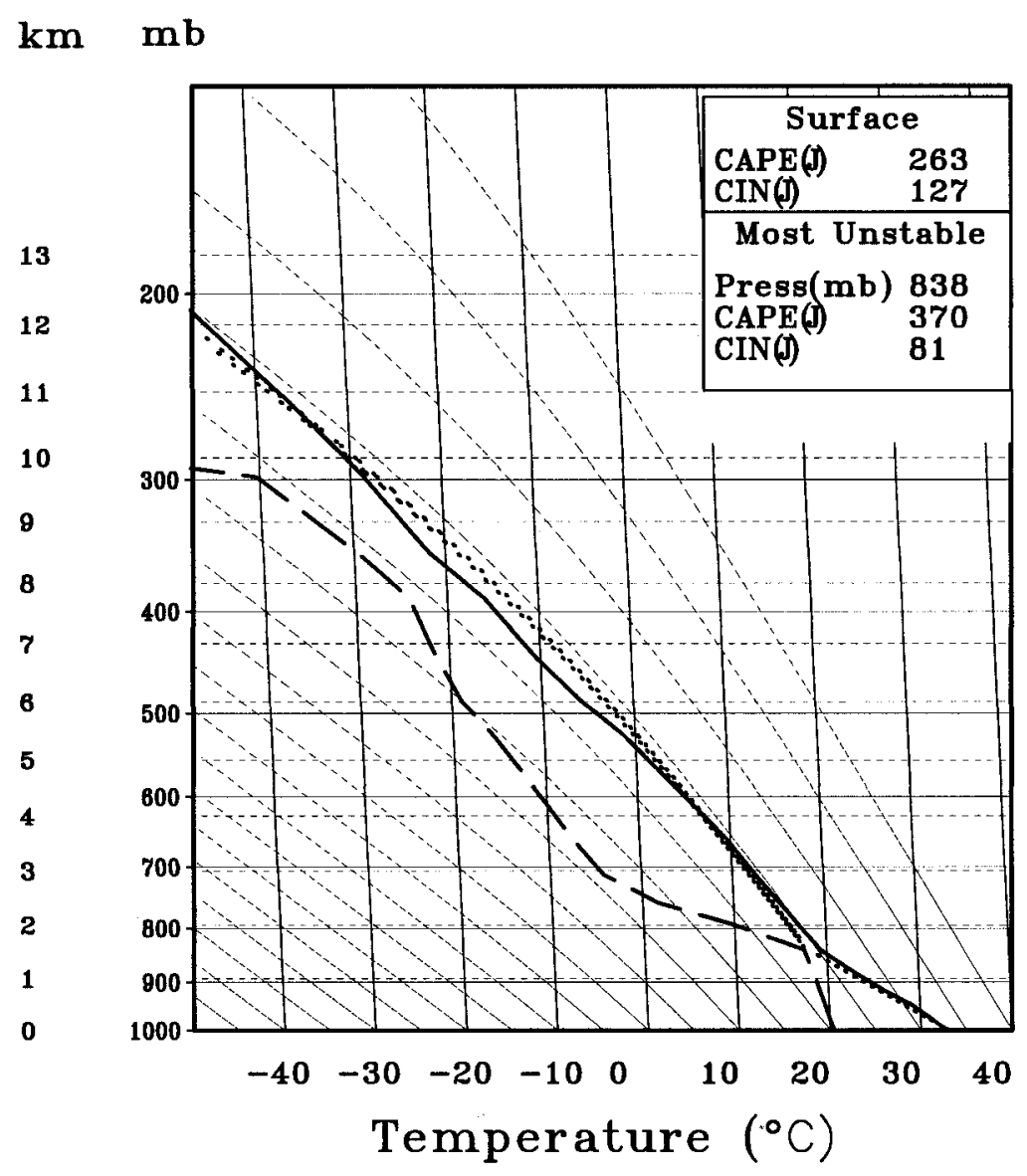

LCL

FIG. 4. Domain-averaged sounding (1400 LT 4 Nov 1990) for the deforestation run corresponding to Fig. 3. Break-period simulation.

linear analysis discussed above. First, the studies assumed dry atmospheric conditions such that the formation of cloud and precipitation does not play a role in the development of the mesoscale circulations. The issue of possible triggering of moist convection by the mesoscale circulations or dry convection was not addressed. Second, the idealized theoretical analysis was not useful in a specific location. In this paper, these two issues are tackled by extending the focus to include the role of moist processes in triggering mesoscale circulation and by combining modeling and observations toward better understanding of these processes in the context of the conditions in Rondônia. We hope this study will help in answering the questions: Are the fish-bone patterns of deforestation in the Amazon region effective in inducing local circulations? Can the existing deforestation patterns significantly alter local cloudiness and rainfall?

\section{Observations}

There is observational evidence that increased afternoon cumulus clouds are related to the variable land cover features. Cutrim et al. (1995) reported that, in Rondônia, Amazonia, shallow cumulus clouds developed over the partially cleared areas during the 1988 dry season. Their findings include 1) the land surface imposes a strong signature on daytime cumulus clouds over the period of a month, 2) surface vegetation cover could be more important than elevation in controlling the development of cumulus clouds, and 3) the deforestation in Rondônia was causing an increase in dryseason afternoon shallow cumulus clouds. In a midlatitude environment, Rabin et al. (1990) presented a case of significant impact of spatial variation in landscape on cumulus cloud formation over a flat terrain in a relatively dry environment. They further studied the atmospheric conditions under which the role of land surface was important. They concluded that the effect of heterogeneous land surface on shallow cumulus clouds is noticeable when the synoptic forcing (fronts and other large scale disturbances) is weak.

The above observational studies have several things in common. First, significant impact of spatially variable land surface on the cumulus clouds may occur when the 
(a)

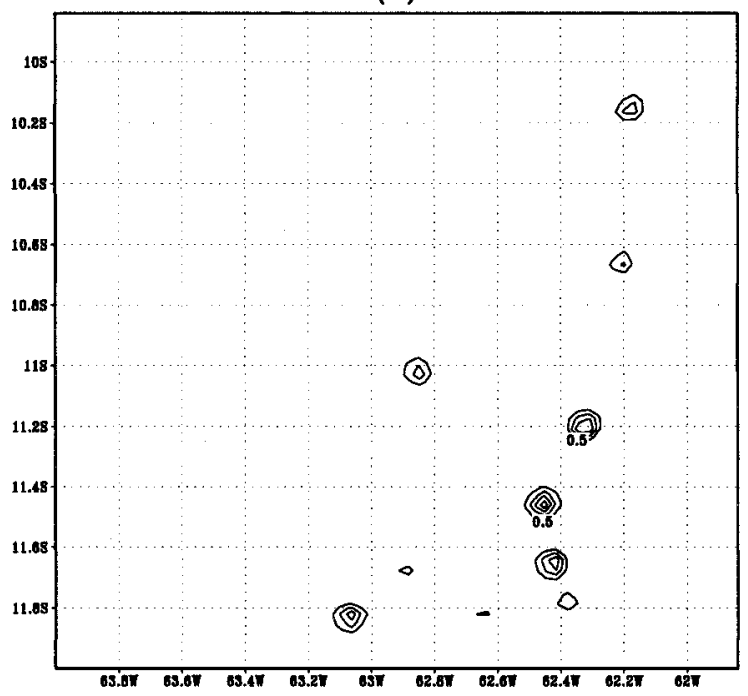

(b)

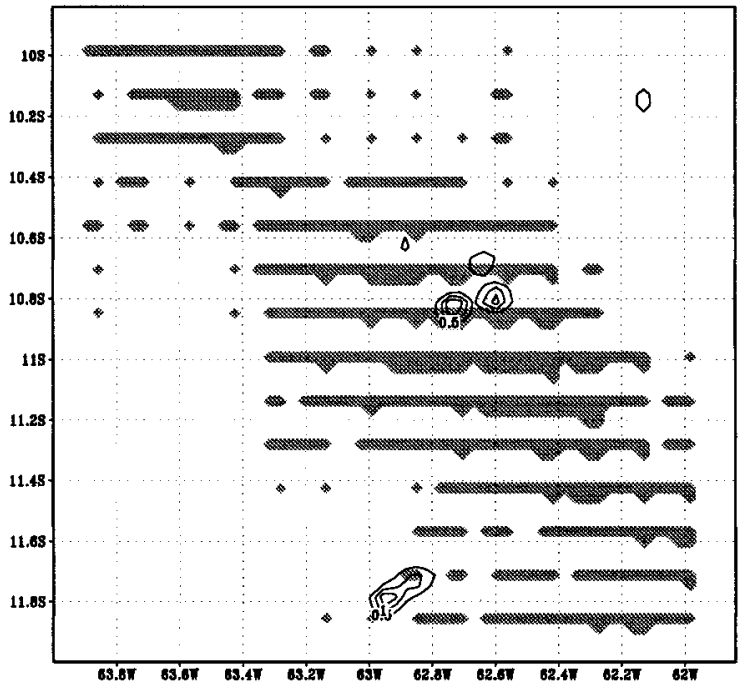

FIG. 5. Same as Fig. 2 but under the condition of reduced synoptic wind.

atmosphere is relatively dry or during a dry season. Second, the resultant cumulus clouds are shallow. Last, a weak large-scale forcing is a favorable condition for the forcing of cumulus clouds by spatially variable land cover.

\section{Rationale}

Moist convection in the atmosphere results from processes over a wide range of scales. Synoptic low pressure disturbances $\left(\sim 10^{3} \mathrm{~km}\right)$ are responsible for extensive cloudiness and precipitation. At local scales $\left(\sim 10^{\circ}\right.$ $\mathrm{km}$ ), diurnal development of turbulent flow in the plan- (a)

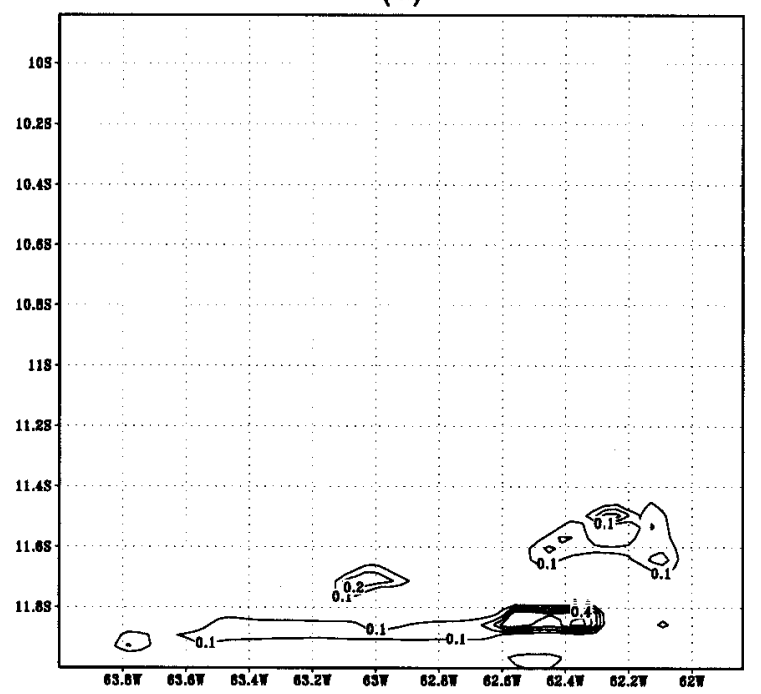

(b)

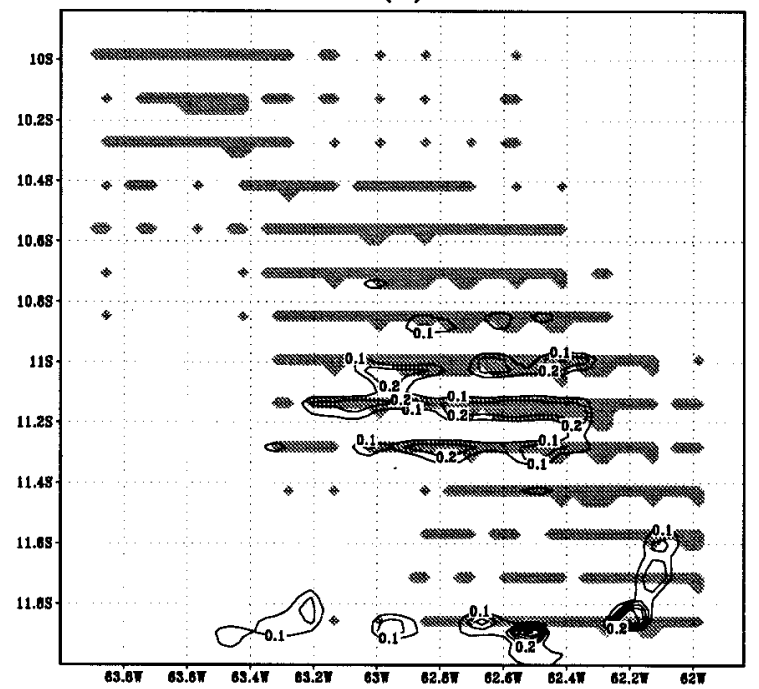

FIG. 6. Cloudiness at 1400 LT 4 Nov 1990 [vertically integrated liquid cloud water $\left(\mathrm{kg} \mathrm{m}^{-2}\right)$ ] for (a) the control run and (b) the deforestation run. Break-period simulation under the condition of reduced synoptic wind.

etary boundary layer could also trigger moist convection, leading to scattered cumulus clouds. Mesoscale circulations induced by land surface heterogeneities, occurring at a scale in between $\left(\sim 10^{1}-10^{2} \mathrm{~km}\right)$, arguably may provide an additional mechanism for triggering moist convection. The mesoscale circulation mechanism is highly dependent on the magnitude and length scale of the heterogeneity of the land surface as well as on the synoptic conditions. In an absolutely stable atmosphere, mesoscale circulations are inhibited; hence, they make no contribution to triggering of moist convection. In a conditionally unstable atmosphere, in which there 


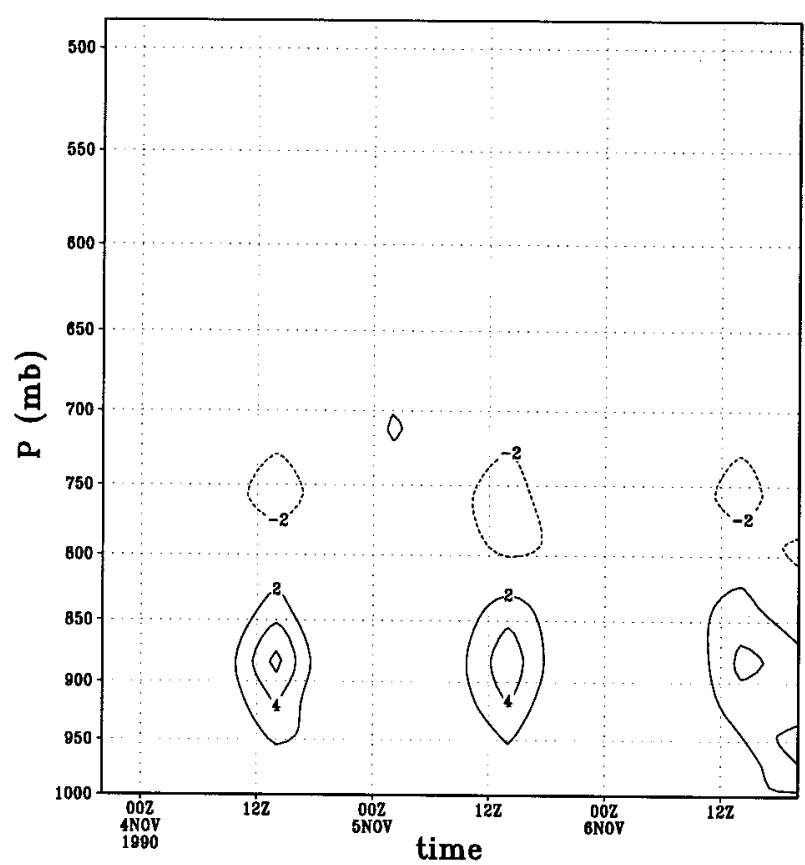

FIG. 7. Mesoscale heat flux $\left(\mathrm{W} \mathrm{m}^{-2}\right)$ caused by the variable land cover. Break-period simulation under the condition of reduced synoptic wind.

is a small energy barrier near the surface, the turbulent flow within the planetary boundary layer can trigger moist convection even over a homogeneous land surface. Under the above conditions, the mesoscale circulations play little role in triggering convection. The hypothesis to be tested here is that mesoscale circulations are expected to be relatively important during periods of time when the atmosphere is conditionally unstable with a moderate energy barrier near the surface and in the absence of strong synoptic systems. Under the condition of weak synoptic forcing, mesoscale circulations could help the air parcels to overcome the energy barrier and to trigger moist convection.

Three climatic regimes have been identified over Rondônia, Amazonia. A typical dry-season day is characterized by a stable sounding profile with little convective available potential energy (CAPE). The wet (rainy) season in the region is characterized by an unstable sounding with relatively large CAPE and small energy barrier. Between the dry and wet seasons, there is a period of time over Rondônia when the synoptic disturbances are relatively weak. This transition time is called break period. In this study, synoptic forcing refers to the large-scale atmospheric environment characterized by stability and synoptic wind. Simulation times have been selected in the middle of the seasons so that the atmospheric stability condition is likely to be representative.

A simulation with observed land cover patterns is labeled a deforestation run. A simulation with uniform forest land cover conditions is labeled a control run. This difference (i.e., land cover condition) is the only one between a deforestation run and its corresponding control run. All other initial and boundary conditions remain the same. The impact of variable land cover on cloudiness and rainfall patterns can be seen by comparing a deforestation run with the corresponding control run.

\section{Numerical model}

The Fifth-Generation Pennsylvania State UniversityNational Center for Atmospheric Research (Penn StateNCAR) Mesoscale Model, version 2 (MM5V2) was chosen to perform the numerical simulations. A detailed description of MM5 can be found in Grell et al. (1994) and hence will not be repeated here. One desired feature of MM5 for the purpose of this study is that moist convection processes can be resolved explicitly when using small grid size $(<\sim 10 \mathrm{~km})$. Other important features of the model include the dynamics of surface energy balance for the diurnal cycles of surface heat fluxes and parameterizations of PBL and land surface processes.

Nested (two) domains (Fig. 1) have been used to provide realistic boundary conditions for the area of interest and to minimize boundary effects (for instance, clouds and rainfall tend to occur along the boundary when using a single-domain setup). The outer domain is an area of $480 \mathrm{~km} \times 480 \mathrm{~km}$ with a grid size of $12 \mathrm{~km}$. The inner domain of $240 \mathrm{~km} \times 240 \mathrm{~km}$ with a grid size of $4 \mathrm{~km}$ is located at the center of the outer domain, covering part of Rondônia where the fish-bone pattern of deforestation has been observed. The atmosphere up to $100 \mathrm{hPa}$ is divided into $24 \sigma$ levels $(1.00,0.99,0.98$, $0.96,0.93,0.89,0.85,0.80,0.75,0.70,0.65,0.60,0.55$, $0.50,0.45,0.40,0.35,0.30,0.25,0.20,0.15,0.10,0.05$, and 0.00$)$. The nonhydrostatic option of the model was used for all simulations. No convective parameterization was needed for the inner domain in which moist convective processes were resolved explicitly, and the Grell convection scheme was used for the outer domain in accordance with the grid size $(12 \mathrm{~km})$. Other model physics include the Blackadar PBL parameterization, simple ice microphysics, NCAR Community Climate Model, version 2, radiation schemes, and shallow convection processes. Initial and boundary conditions were obtained from National Centers for Environmental Prediction reanalysis data available at the NCAR data archive. All simulations start at 2000 LT and last $72 \mathrm{~h}$, with a time step of $60 \mathrm{~s}$. In the following sections, only the simulation results for the inner domain will be presented.

Land cover data in the form of deforestation percentage (Skole and Tucker 1993) at $16-\mathrm{km}$ resolution was disaggregated onto a $4 \mathrm{~km} \times 4 \mathrm{~km}$ gridded mesh over the inner domain of the model. When the per- 


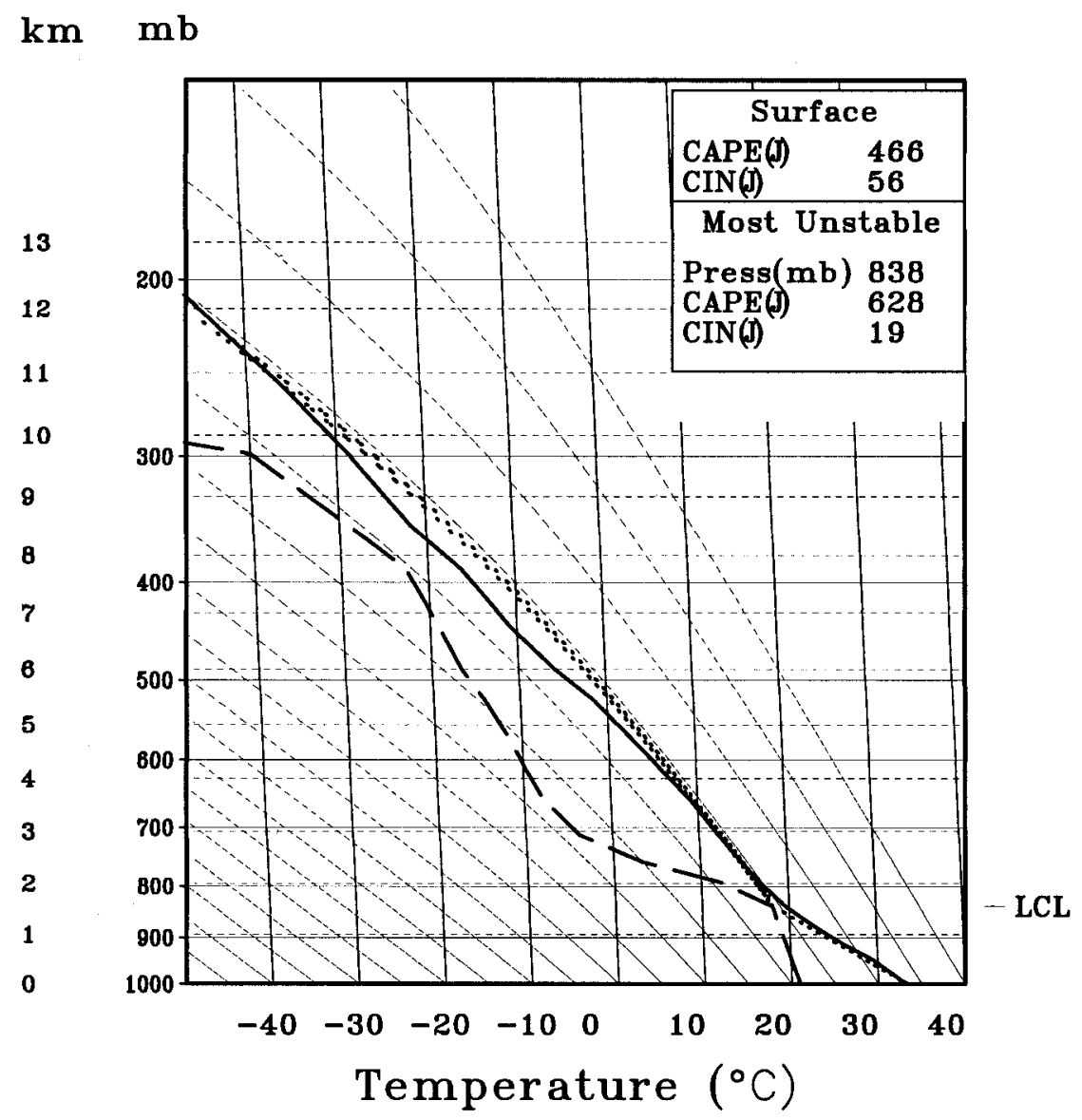

FIG. 8. Same as Fig. 4 but for the deforestation run under the condition of reduced synoptic wind.

centage of deforestation of a 16-km cell, which is divided into 16 (4 by 4 ) 4-km cells in the numerical model, is no more than $6.25 \%$ (i.e., $=100 \% / 16$ ), 1 of the $4-\mathrm{km}$ cells is assumed to be deforested and the other 15 cells are treated as covered by forest. When the deforestation percentage is between $6.26 \%$ and $12.5 \%, 2$ of the 16 4-km cells are assumed to be deforested, and so on. The deforested 4-km cells were arranged side by side to mimic the fish-bone pattern (left to right, starting from the upper-left corner of the 16-km cell).

\section{Simulation results}

In the following, the distributions of 3-day cumulative rainfall and afternoon cloudiness are concentrated on. We expect to see an enhancement of the afternoon cloudiness triggered by the mesoscale circulations and/or the development of PBL because of the (differential) surface heating. The mesoscale circulations will be characterized by the associated mesoscale heat flux (its definition is given in the appendix) because of the unique behavior of the space-time distribution of the mesoscale heat flux (Lynn et al. 1995; Wang et al. 1996, 1998). The basic features of the mesoscale heat flux are different from the corresponding turbulent heat flux, particularly in its vertical distribution. Unlike the turbulent heat flux, which has a maximum at the surface and decreases upward, the mesoscale heat flux increases with height from zero at the surface, reaches a peak at a certain level (depending on the atmospheric stability profile, usually at about $1 \mathrm{~km}$, or the $900-\mathrm{hPa}$ level), then decreases to a negative maximum with a smaller magnitude, eventually vanishing with height. It also has a well-defined periodicity in time that follows the diurnal heat cycle of the land surface. These features will be used to detect the signals of mesoscale circulations and to describe its role in triggering convection.

\section{a. Break period}

In the September-November time frame in Rondônia, referred to as the "break period," the synoptic systems usually are relatively weak in comparison with those in the rainy and dry seasons. It is this break- 
(a) cloudiness ( $2 \mathrm{~km}$ resolution)

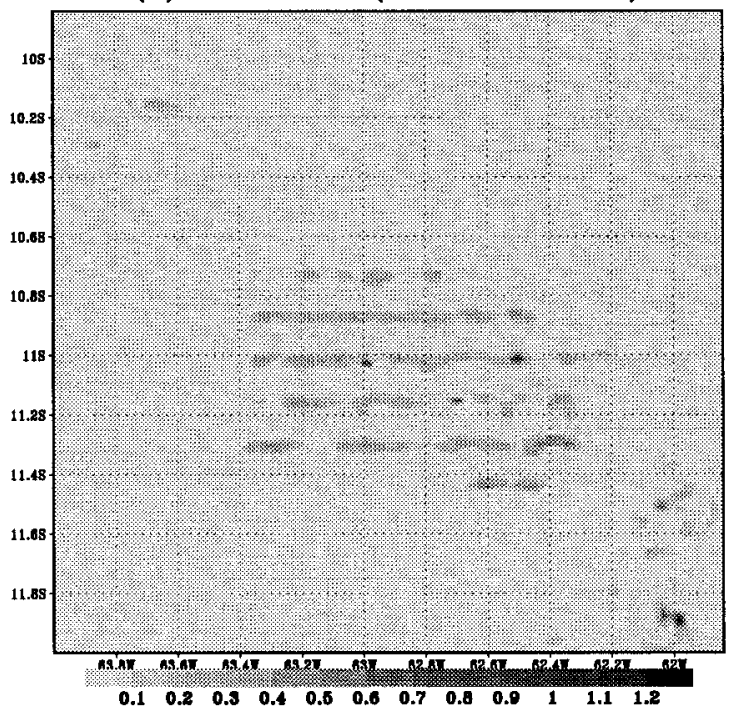

(b) cloudiness ( $4 \mathrm{~km}$ resolution)

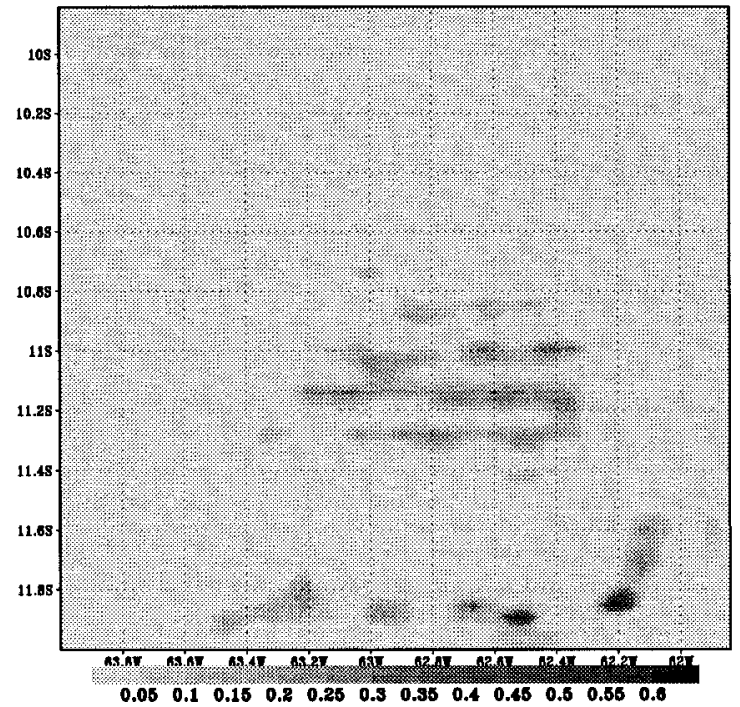

FIG. 9. Cloudiness at 1400 LT 4 Nov 1990 from deforestation runs. (a) $2-\mathrm{km}$ resolution, (b) 4-km resolution. Break-period simulations under the condition of reduced synoptic wind.

period regime in which mesoscale circulations may be active over the heterogeneous land surface and potentially may play a role in shaping the distributions of cloudiness and rainfall. The simulation time was from 2000 LT 3 November to 2000 LT 6 November 1990. The dates were selected arbitrarily, except that they are in the middle of the season so that the synoptic conditions are representative.

The model predicted an insignificant amount of 3-day cumulative rainfall of no more than $0.1 \mathrm{~mm}$ (Fig. 2) at isolated location(s) in the control run and almost no rainfall in the deforestation run. Afternoon cloudiness (a) rainfall (2km resolution)

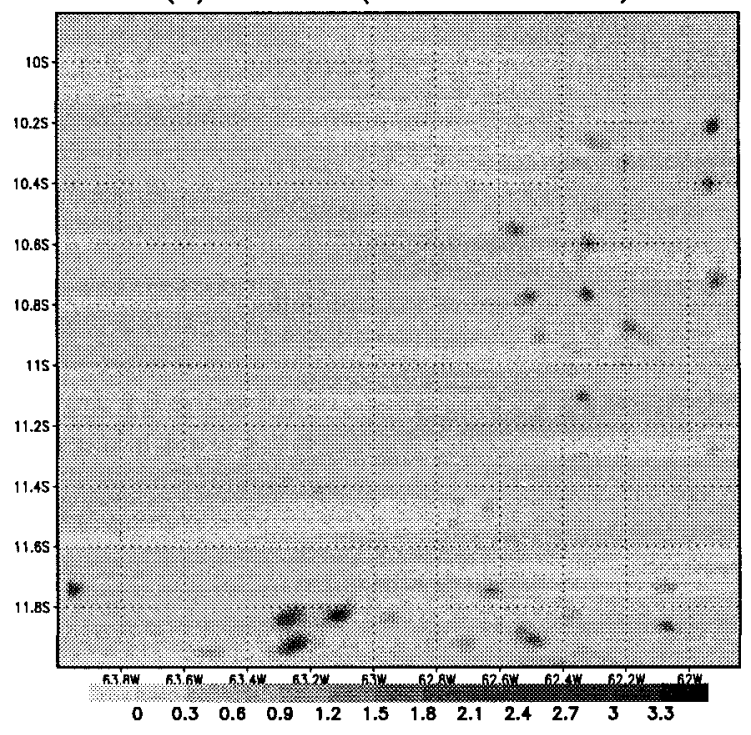

(b) rainfall (4km resolution)

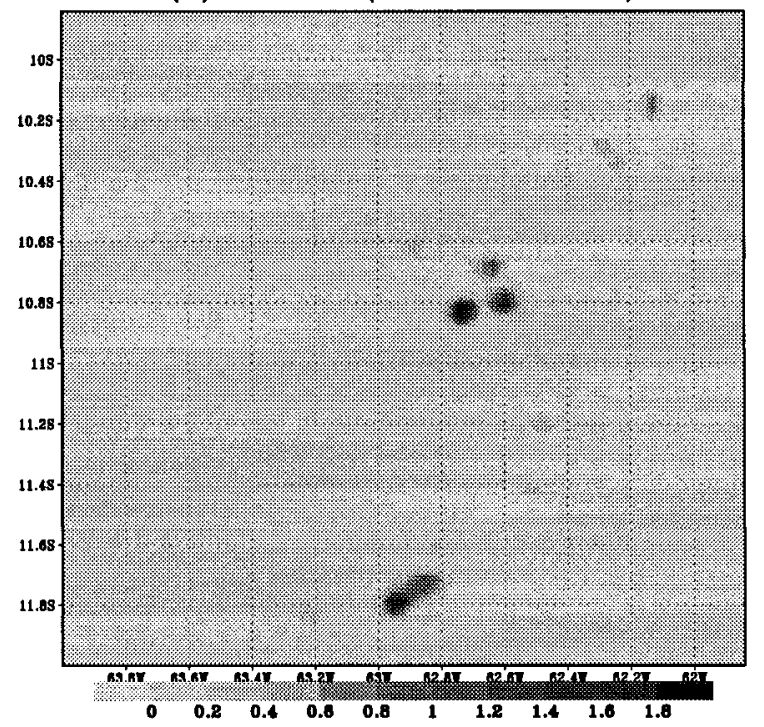

FIG. 10. Seventy-two-hour cumulative (3-6 Nov 1990) rainfall (cm) from deforestation runs. (a) $2-\mathrm{km}$ resolution, (b) $4-\mathrm{km}$ resolution. Break-period simulations under the condition of reduced synoptic wind.

was not observed in either simulation. Apparently, the development of PBL did not trigger convection. Nevertheless, there was convincing evidence that mesoscale circulations were induced over the deforested domain. Figure 3 shows a well-defined structure of mesoscale heat flux caused by the deforestation. The space-time distribution of the mesoscale heat flux was in close agreement with that predicted by the earlier studies (e.g., Lynn et al. 1995; Wang et al. 1996). Lack of afternoon convection indicates that the mesoscale circulations 
(a)

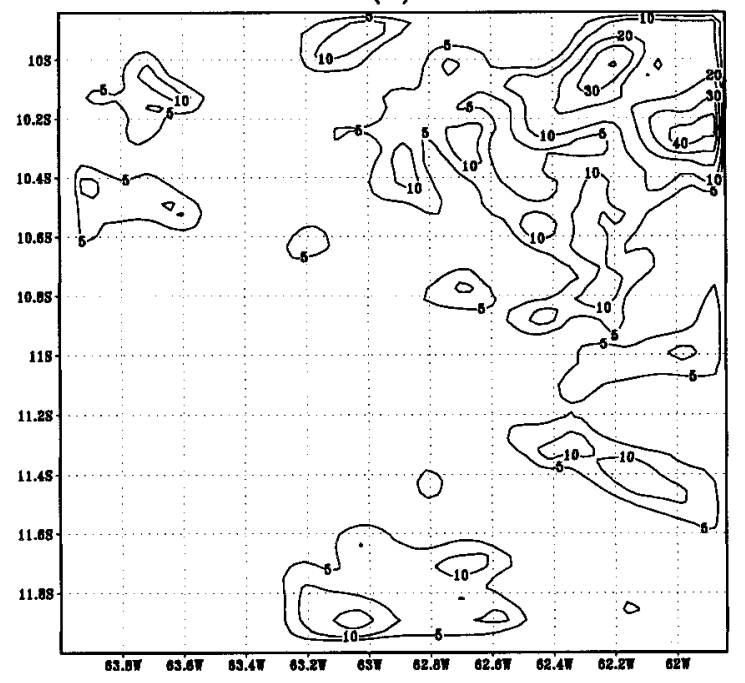

(b)

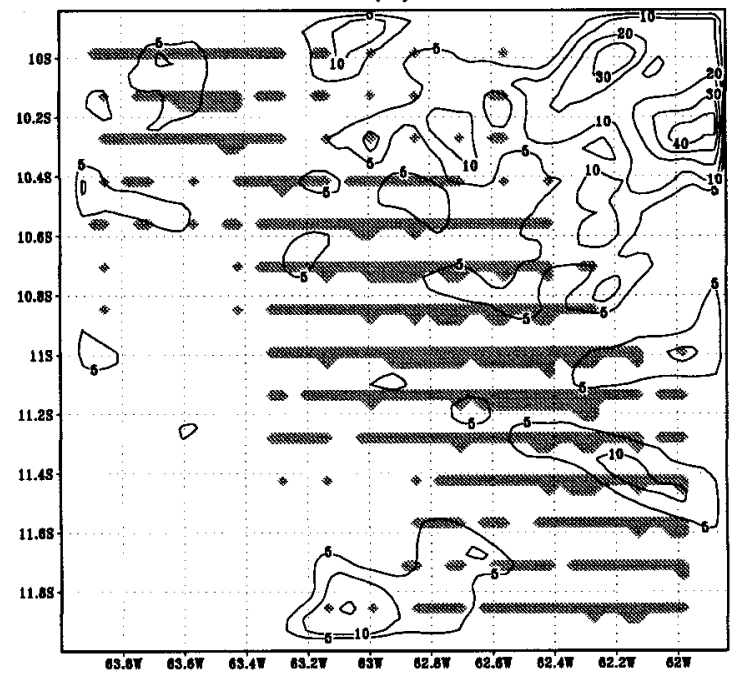

FIG. 11. Cumulative $(72 \mathrm{~h})$ rainfall $(\mathrm{cm})$ for (a) the control run and (b) the deforestation run. Rainy-season simulation for 3-6 Jan 1990.

were not strong enough to overcome the energy barrier in the sounding (Fig. 4) to trigger convection. The sounding profile shows that the most unstable (i.e., highest equivalent potential temperature) level is at $\sim 840$ $\mathrm{hPa}$. The mesoscale circulations, however, were weak near this level (Fig. 3b), at which the mesoscale heat flux was vanishing.

This experiment was repeated using a weakened synoptic forcing by reducing the magnitude of the synoptic wind by an arbitrary factor of 10 (the largescale convergence and/or divergence was reduced accordingly). The corresponding simulated rainfall and afternoon cloudiness are shown in Figs. 5 and 6. The (a)

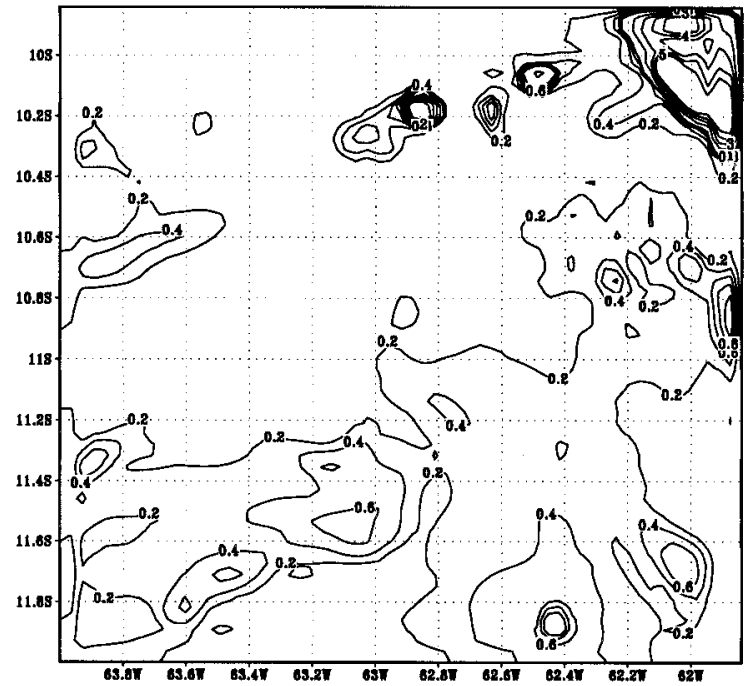

(b)

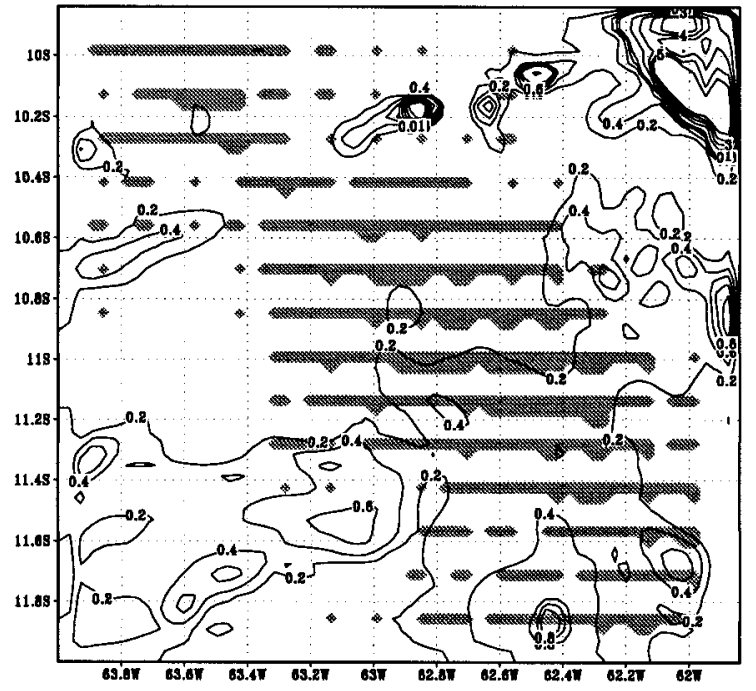

FIG. 12. Cloudiness at 1400 LT 4 Jan 1990. (a) Control run and (b) deforestation run. Rainy-season simulation. rainfall patterns in the deforestation and control runs were qualitatively similar, although the locations of the sporadic rain cells were somewhat different. Note that they did not resemble the land cover patterns. Enhanced cloud was simulated over the deforested locations (Fig. 6b), however. The clouds were observed at levels between 900 and $800 \mathrm{hPa}$. Enhanced cloudiness over the deforested areas also occurred in the afternoon of the second and third simulation day (results not shown). The mesoscale circulations measured by the the mesoscale heat flux (Fig. 7) were stronger under this weakened synoptic wind condition. Figure 7 clearly shows that the mesoscale cir- 


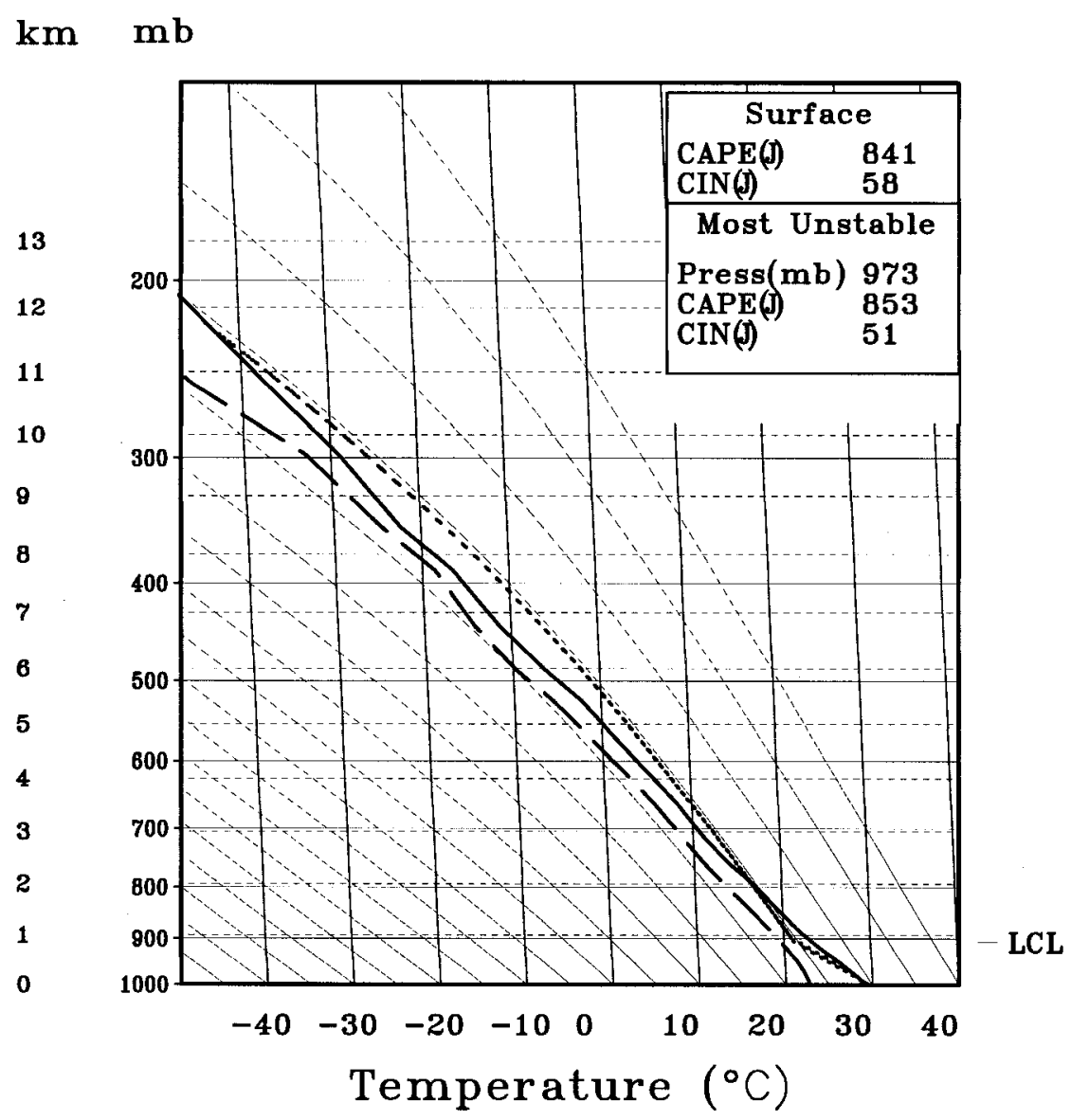

FIG. 13. Domain-averaged sounding (1400 LT 4 Jan 1990) for the control run corresponding to Figs. 11a and 12a. The heavy solid line represents the temperature and the heavy long-dashed line represents the dewpoint temperature. The short-dashed line is the air parcel path starting from the surface. Rainy-season simulation.

culations reached higher altitudes than the most unstable level of $\sim 840 \mathrm{hPa}$ (see the sounding profile displayed in Fig. 8). Moreover, the atmosphere was less stable, as indicated by greater values of CAPE and smaller values of convective inhibition negative energy (CIN) (cf. Fig. 4 and Fig. 8). This environment turned out to be one in which the mesoscale circulations were responsible for triggering the enhanced cloudiness, because the PBL structure in this simulation was very much the same as in the previous case in terms of turbulent sensible heat flux and boundary layer height. The enhanced afternoon cloudiness consisted of low-level cumulus clouds at the $\sim 800-\mathrm{hPa}$ level. The low-level cumulus clouds produced little precipitation, as seen in Fig. 5, which shows that the sparse rainfall cells do not overlap with the locations of the clouds (Fig. 6). These results suggest that deforestation may enhance afternoon cloudiness but contributes little to local rainfall.

There is a concern about whether the use of 4-km resolution faithfully resolves the processes of clouds and rainfall. Previous studies (e.g., Weisman et al. 1997) suggested that numerical studies of tropical convection, for which CAPE often is much less than that associated with the midlatitude cases, had to use small horizontal grid resolution $(<4 \mathrm{~km})$ to resolve properly the weaker convective updraft and downdraft. To study the model behavior as a function of resolution, the above breakperiod simulation was repeated under reduced synoptic wind condition. The resultant distributions of afternoon cloudiness and rainfall are shown in Figs. 9 and 10, respectively. It turned out that the simulated cloudiness and rainfall using 2-km resolution were in good agreement, at least qualitatively, with those in the corresponding simulation using 4-km resolution, although the $2-\mathrm{km}$ resolution simulation resulted in larger rain rates and higher cloud water content. Such consistency gave us confidence that the essential aspects of the landatmosphere interaction over the deforested region under study would be captured by the model with $4-\mathrm{km}$ res- 
(a)

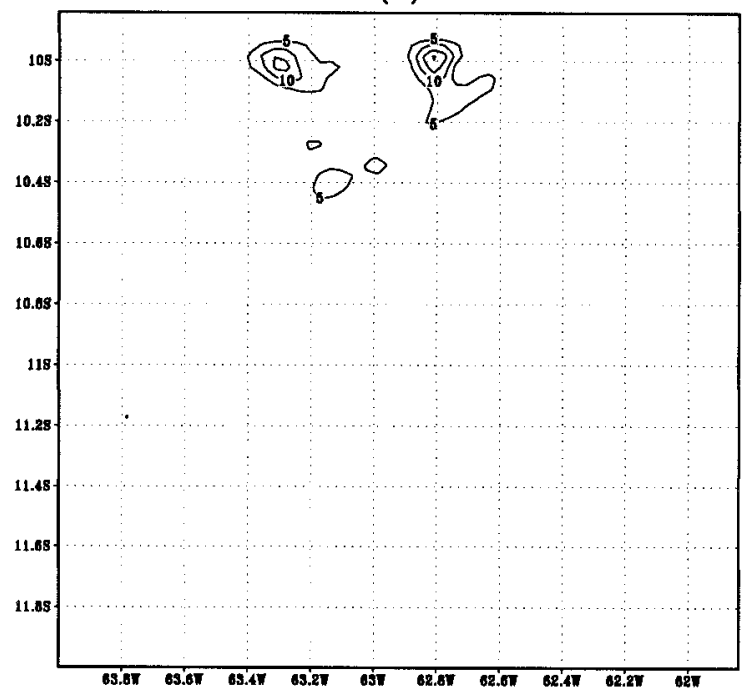

(b)

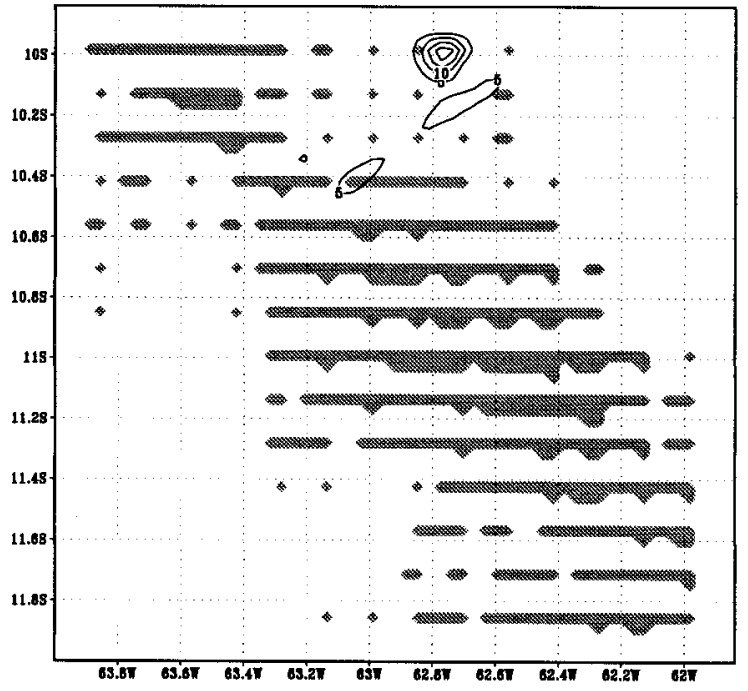

FIG. 14. Same as Fig. 11 but with the synoptic wind reduced by a factor of 10

olution. Because of the limited available computing resources, the rainy-season and dry-season simulations were conducted using 4-km resolution.

\section{b. Rainy season}

The rainy season in Rondônia extends from December to April, during which large-scale convection is responsible for the observed widespread and persistent rainfall. The rainy-season simulations cover 2000 LT 3 January to 2000 LT 6 January 1990. Figure 11 shows the 3-day cumulative rainfall. Simulated afternoon cloudiness at 1400 LT 4 January (the first simulation (a)

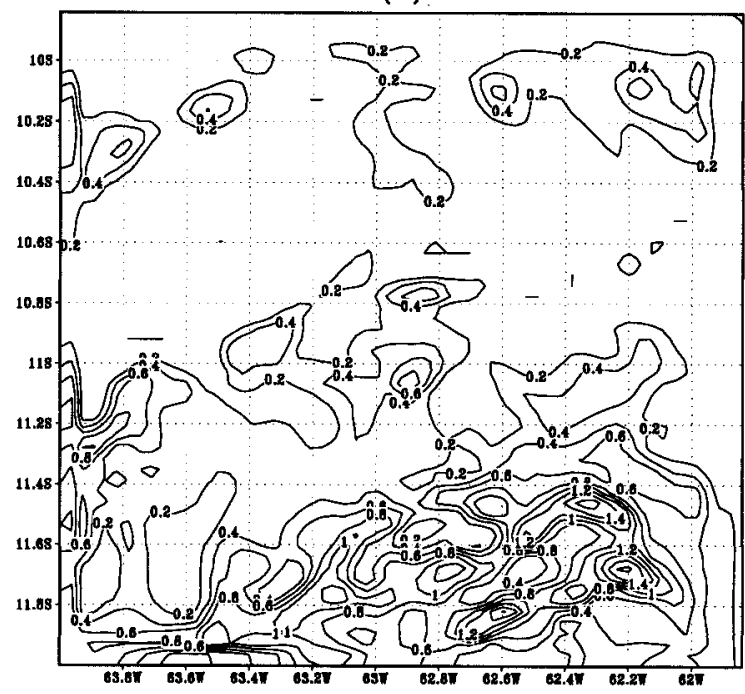

(b)

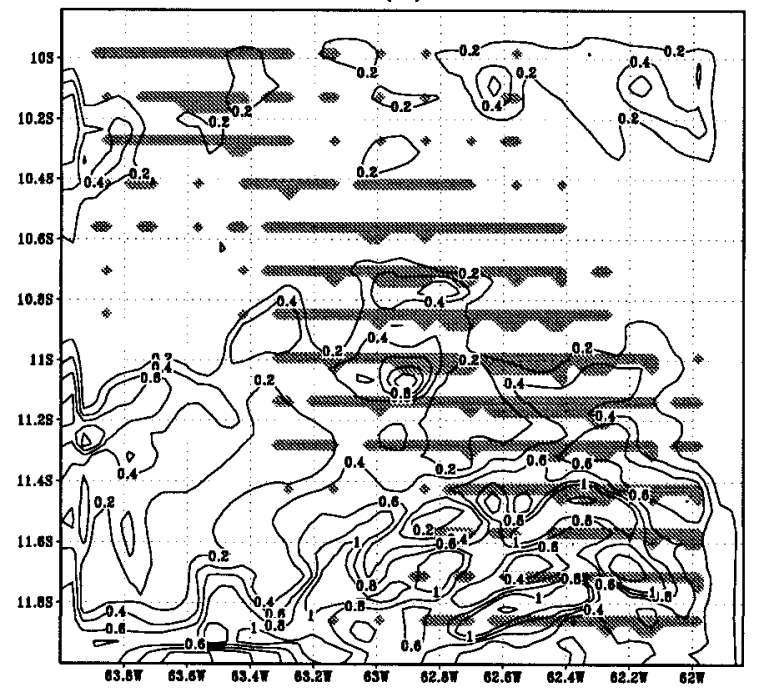

FIG. 15. Same as Fig. 12 but with the synoptic wind reduced by a factor of 10 .

day) is illustrated in Fig. 12. Sounding profiles (temperature and dewpoint temperature in Fig. 13) indicate that the atmosphere is conditionally unstable with relatively large CAPE values, small values of CIN, and a low most-unstable level of $\sim 970 \mathrm{hPa}$, which was very close to the surface. Such a sounding implies a much more unstable atmosphere than that in the break period shown above (Fig. 4). Active deep convection and intensive rainfall were obtained in both the deforestation and the control runs. The distributions of the high clouds and rainfall from the control and deforestation runs were nearly identical. Shallow clouds did not occur in the rainy-season simulations. Moreover, they had no similarity to the patterns of land cover. Variability in the 
(a)

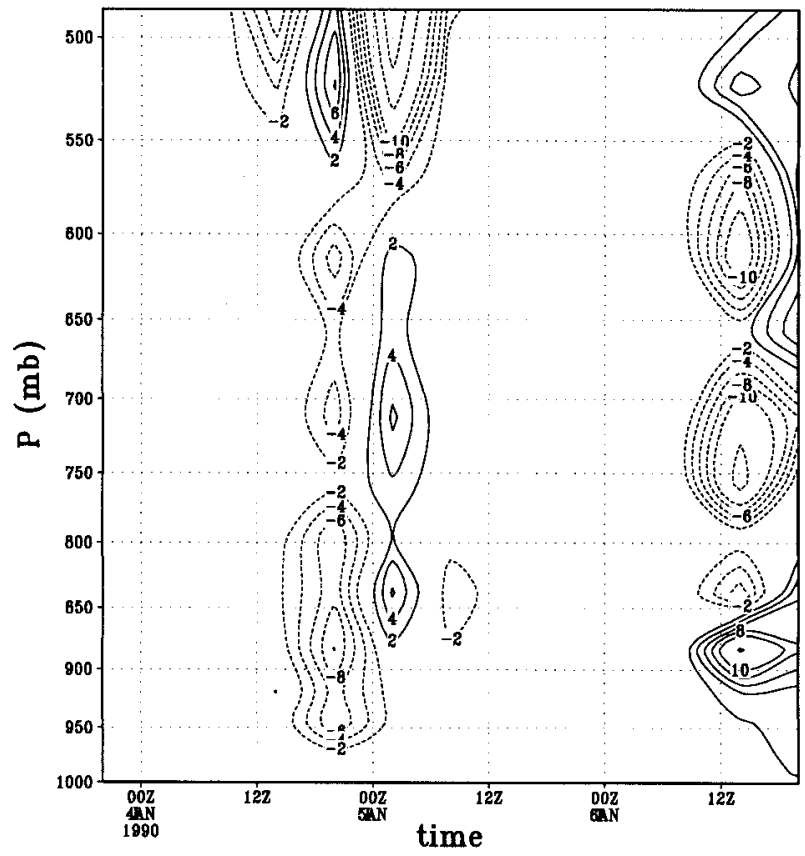

(b)

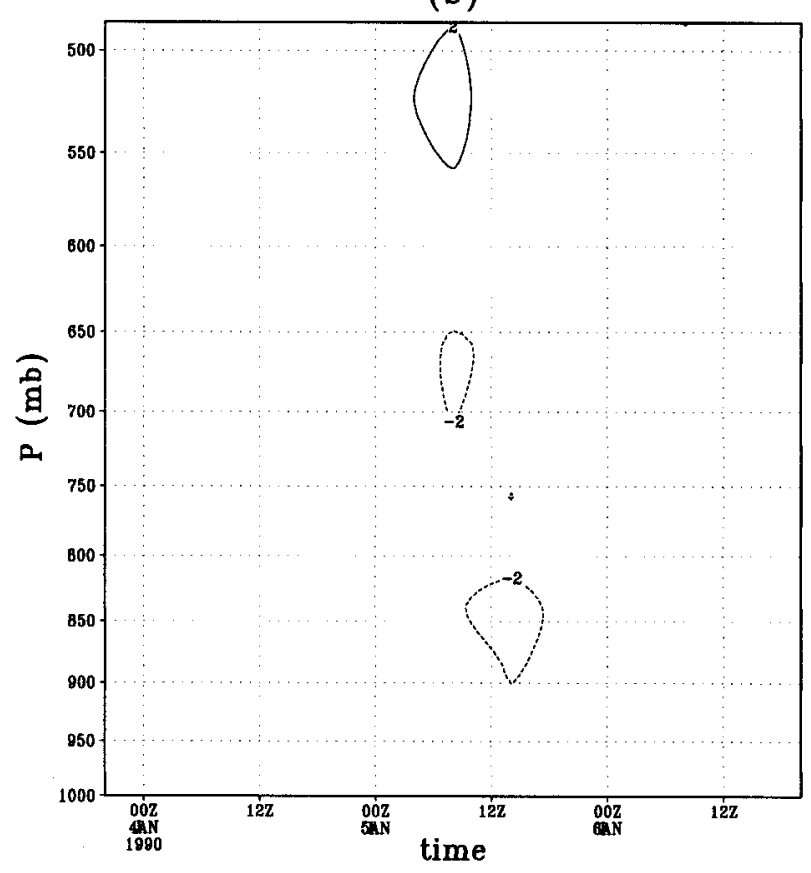

FIG. 16. Mesoscale heat flux ( $\mathrm{W} \mathrm{m}^{-2}$ ) caused by the variable land cover. (a) Original synoptic wind condition, (b) reduced synoptic wind condition. Rainy-season simulations.

land cover condition clearly played no role in shaping the distribution of cloudiness and rainfall.

The break-period simulations presented previously show that the deforestation may affect the convection processes in an environment of weakened synoptic (a)

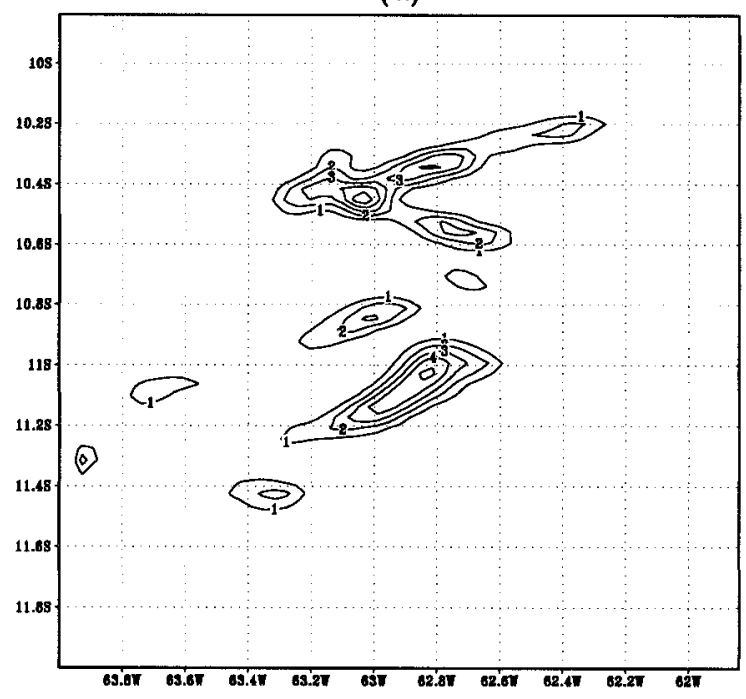

(b)

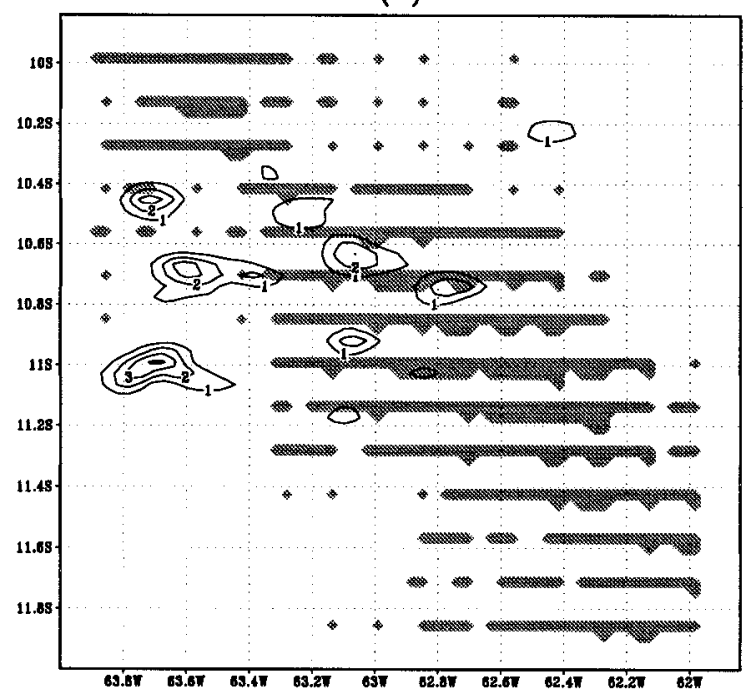

FIG. 17. Cumulative $(72 \mathrm{~h}$ ) rainfall $(\mathrm{cm})$ for (a) the control run and (b) the deforestation run. Dry-season simulation for 30 Jun-3 Jul 1990.

wind. The experiment was repeated again with the initial and boundary values of wind velocities reduced by a factor of 10 and all other conditions remaining unchanged. The reduction in the synoptic wind led to considerably different rainfall and cloudiness fields (Figs. 14 and 15). The spatial coverage of afternoon cloudiness under the weakened synoptic wind condition was greatly reduced. The clouds also occurred at different locations. As in the previous simulation, deep convection led to high-level clouds above $500 \mathrm{hPa}$ with a peak at around $300 \mathrm{hPa}$. No low-level clouds were generated. The area receiving rainfall shrank considerably; only isolated rainfall cells were simulated. The reduction in the cloud- 
(a)

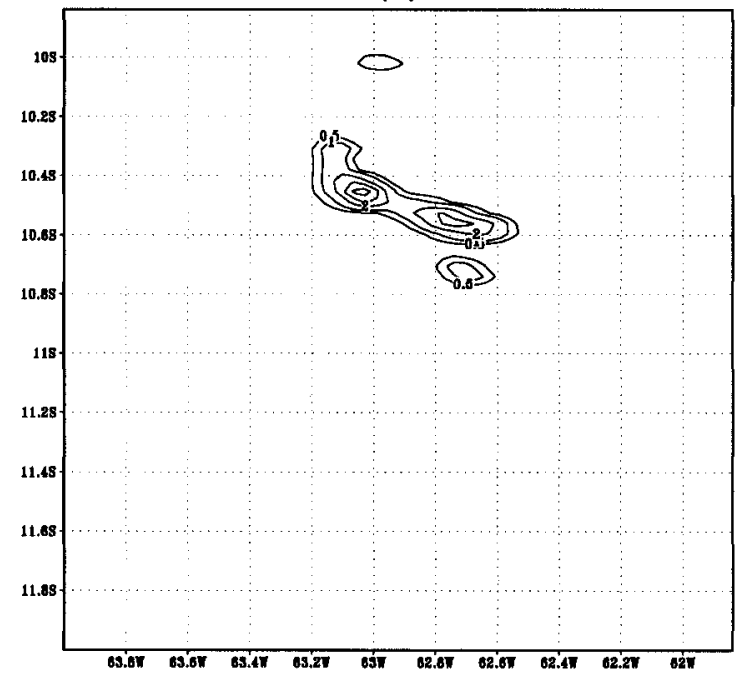

(b)

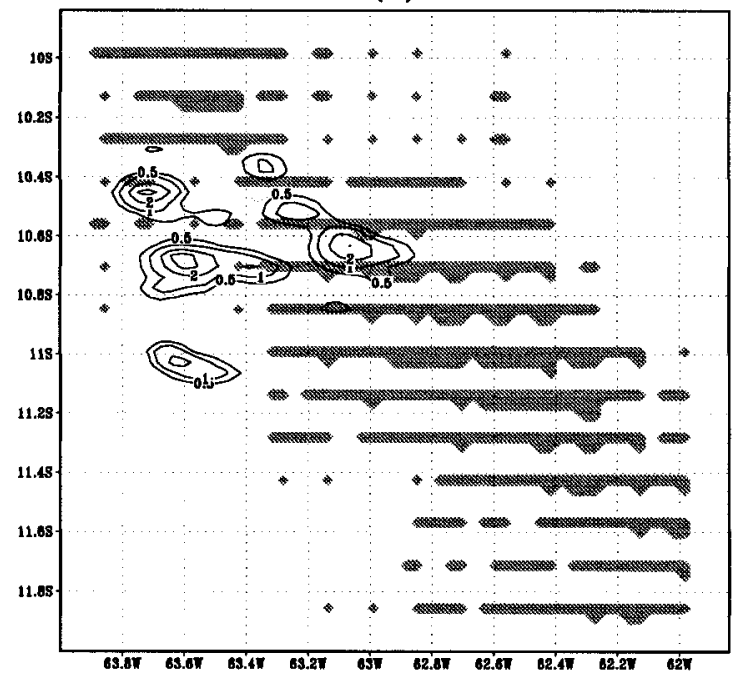

FIG. 18. The first-afternoon rainfall (cm) (1600-2000 LT). (a) Control run and (b) deforestation run. Dry-season simulation.

iness and rainfall presumably was due to the weakened large-scale ascending motion of the air and reduced convergence of moisture. This cause was consistent with the fact that the sounding was associated with a muchsmaller CAPE (not shown here), implying a less-unstable atmosphere relative to the previous case. Again, the patterns of cloudiness and rainfall bear no similarity to the patterns of land cover. Thus the land surface played little role in shaping the distribution of clouds and rainfall. Although the rainfall distributions of the control run and the deforestation run are not identical, they do share some common basic features. The rainfall covered a small area of the domain in both simulations. The precipitation occurred at the same locations, except for the additional rain cell in the control run. The peak intensity of rainfall was comparable. Above all, there was no correlation between the pattern of rainfall and that of land cover in either run. The land surface processes apparently were irrelevant to the convection processes over this period of time.

It would be safe to conclude that mesoscale circulations did not develop over this period of time, because the mesoscale heat flux was essentially zero (Fig. 16b) under the condition of reduced synoptic wind. The heat flux for the case of the original synoptic wind condition given in Fig. 16a, on the other hand, needs to be scrutinized more carefully. It behaves very differently from the knowledge of mesoscale heat flux described at the beginning of this section. The mesoscale heat flux should decay upward from the level of its maximum near $1 \mathrm{~km}$ or $900 \mathrm{hPa}$, but Fig. 16a shows a periodicity with height. It should be positive near the surface, but negative values were seen throughout the afternoon of 4 January in Fig. 16a. In addition, it has been shown that the magnitude of mesoscale heat flux decreases with synoptic wind, but Fig. 16 shows the opposite. We argue that what is shown in Fig. 16a is not a signal of mesoscale heat flux but is an artifact resulting from departures from the idealized synoptic conditions (i.e., horizontally invariant temperature and zero large-scale vertical velocity) used in the definition and the calculation of mesoscale heat flux (see the appendix).

\section{c. Dry season}

A dry season in Rondônia covers the period of May through August. The dry-season simulation is from 2000 LT 30 June to 2000 LT 3 July 1990. Moderate 3 -day cumulative rainfall was simulated in both the control and deforestation runs (Fig. 17), and the difference between the corresponding rainfall patterns was evident. In particular, precipitation from the deforestation run (Fig. 18b) had a broader coverage than that from the control run (Fig. 18a) during the first afternoon, when localized deep convection occurred over the deforested region and led to precipitating high clouds (discussed below). The organization of the rainfall (Fig. 18b) reflects a land cover signature with the locations of rain cells slightly shifted toward the northwest relative to the deforested areas because of the prevailing wind. During the second and third days of simulation, the patterns of rainfall in the deforestation run (not shown) looked to be random, which did not reflect the land cover, and were not different qualitatively from that in the corresponding control run.

As in the case of the break period under weakened synoptic wind condition, an enhancement of shallow cumulus clouds (near the 800-hPa level) (Figs. 19 and 20) was simulated in the afternoon of the first day of simulation over the deforested areas. Enhanced high cumulus clouds (near the 300-hPa level) (Fig. 21) were also simulated over the partially cleared areas, reflecting 
(a)

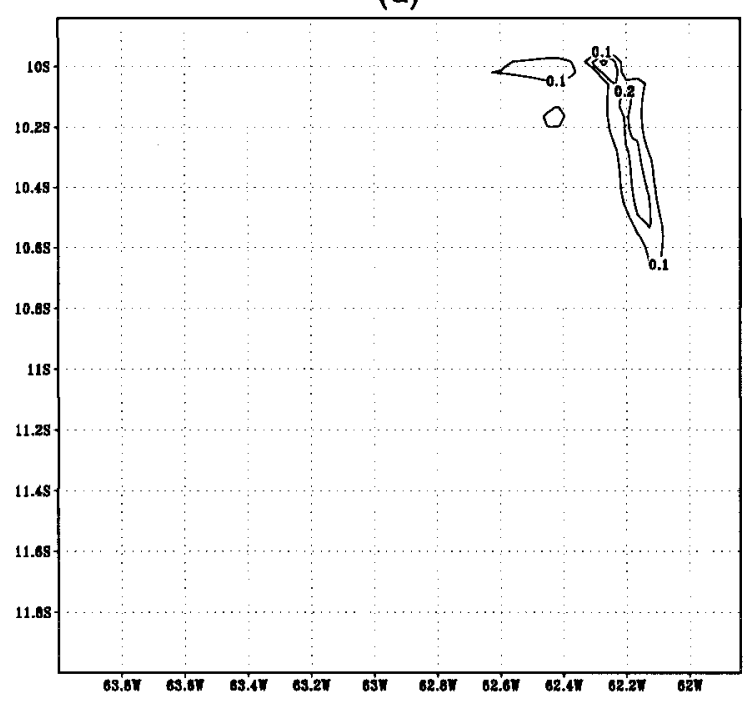

(c)

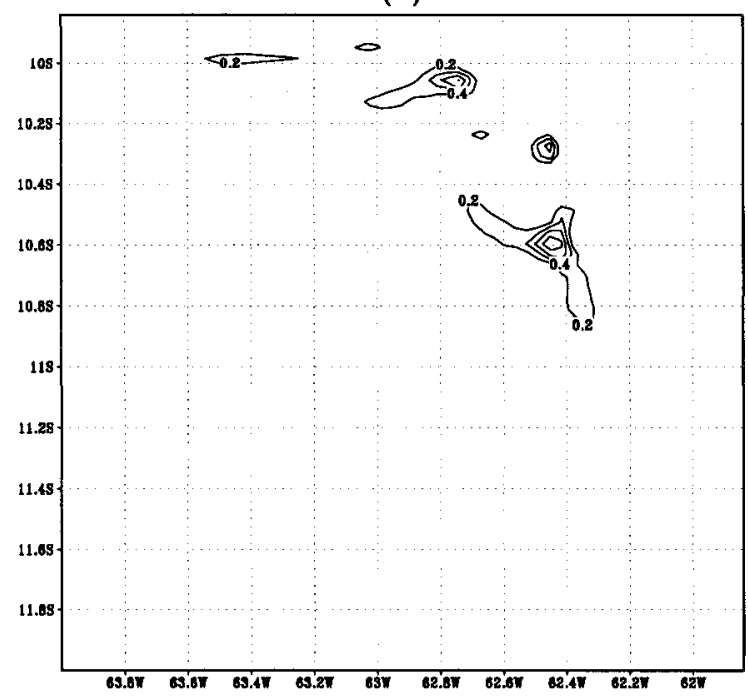

(b)

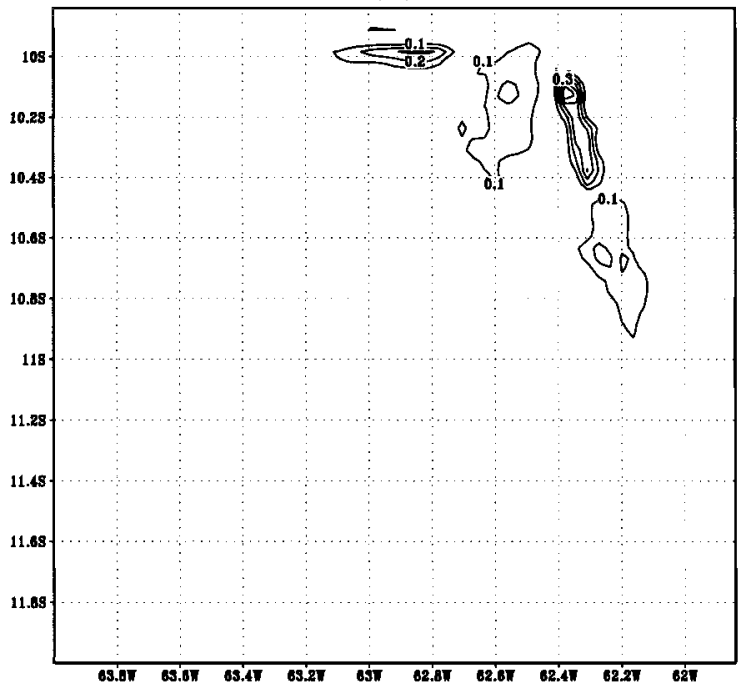

(d)

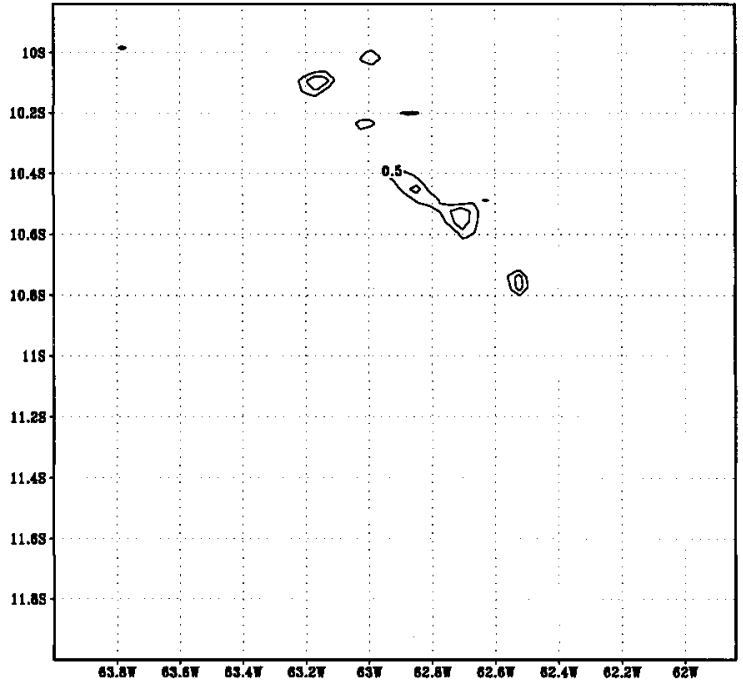

FIG. 19. Low cumulus clouds (vertically integrated cloud water up to $700 \mathrm{hPa}$ ) on 1 Jul 1990 (first day of simulation). (a) 1400 , (b) 1500, (c) 1600, and (d) 1700 LT. Control run. Dry-season simulation.

the pattern of rainfall shown in Fig. 18b. These precipitating high cumulus clouds, contrary to the nonprecipitating shallow clouds, contributed local rainfall (Fig. 18b). On the third day, a weaker enhancement of afternoon shallow clouds was simulated in the deforestation run (Figs. 22 and 23). The majority of the enhanced shallow clouds were simulated over the deforested patches as expected, following closely the patterns of land cover. They were short-lived clouds, lasting about $4 \mathrm{~h}$ starting from $1400 \mathrm{LT}$ on the first day, and from 1500 LT on the third day. Sporadic low clouds also occurred in the second afternoon but with no resemblance to the land cover pattern (Fig. 24).

There were low-level clouds in the upper-right corner of the domain in both the control and deforestation runs in the afternoon of the first day (Figs. 19a,b and 20a,b). Mesoscale circulations certainly played no role in triggering this latter group of clouds because of the lack of differential heating over that part of the domain covered by uniform forest. A relative large CAPE $(\sim 600 \mathrm{~J})$ at that location in the domain provided a favorable condition for convection triggered by the development of turbulence in the PBL. The lower-left corner of the domain, also covered by forest, exhibited a much smaller value of CAPE $(\sim 200 \mathrm{~J})$. This part of the domain was cloud free, although it was subjected to a stronger surface heating (i.e., greater surface sensible heat flux, not shown). The question now is, what causes the enhanced 
(a)

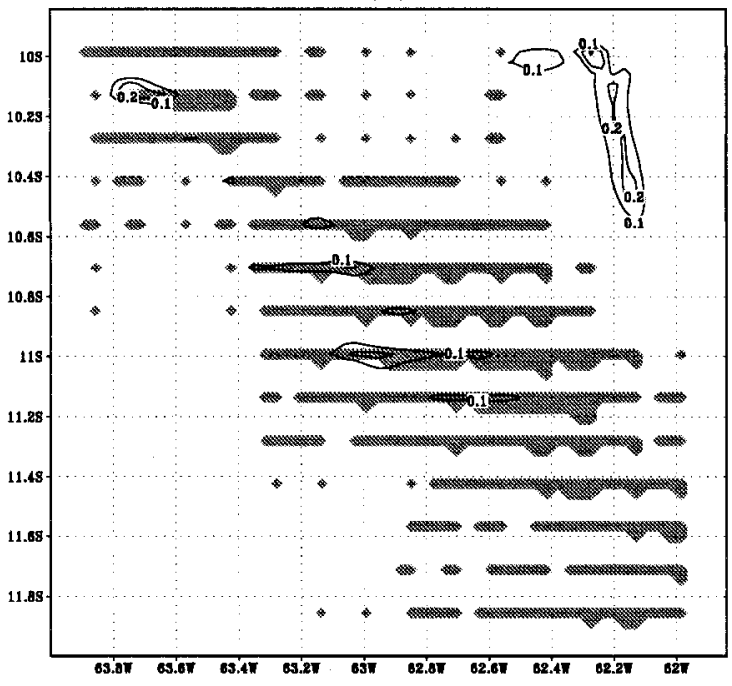

(c)

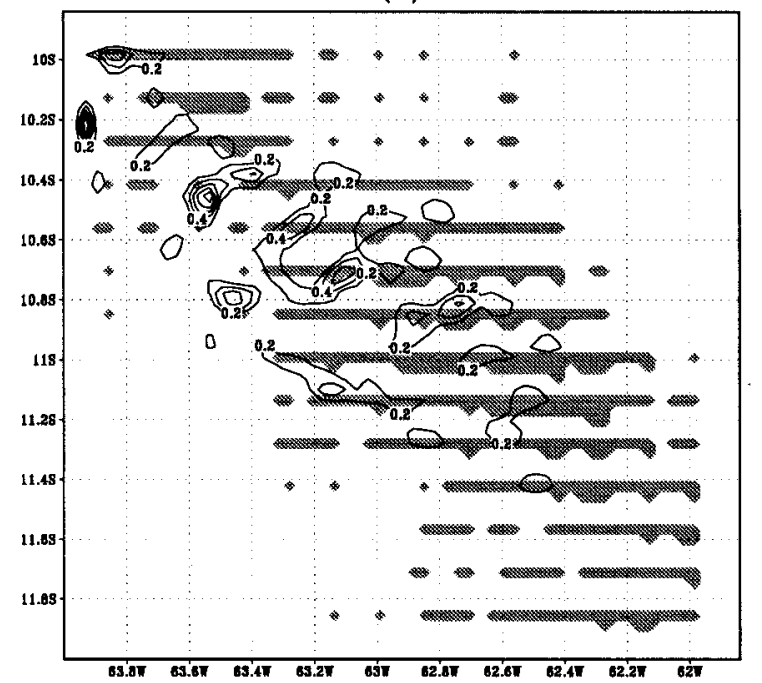

(b)

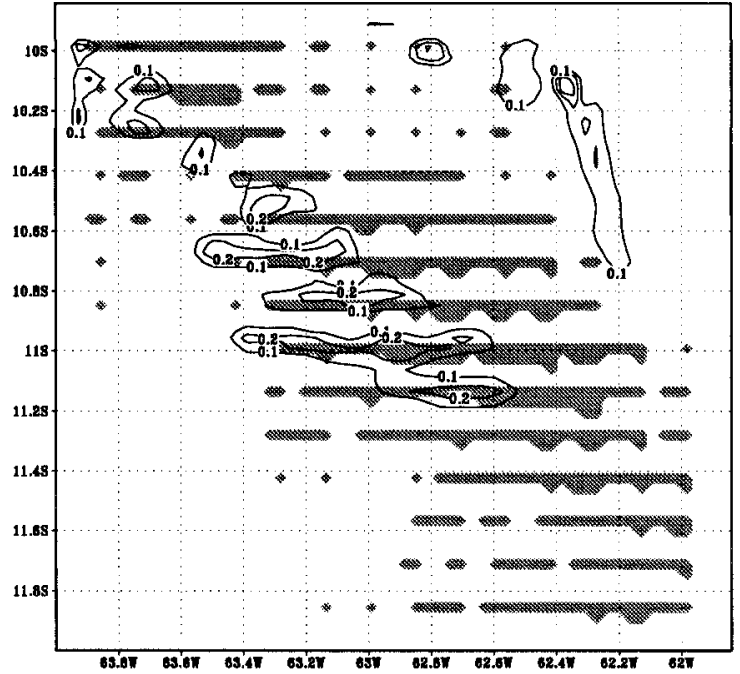

(d)

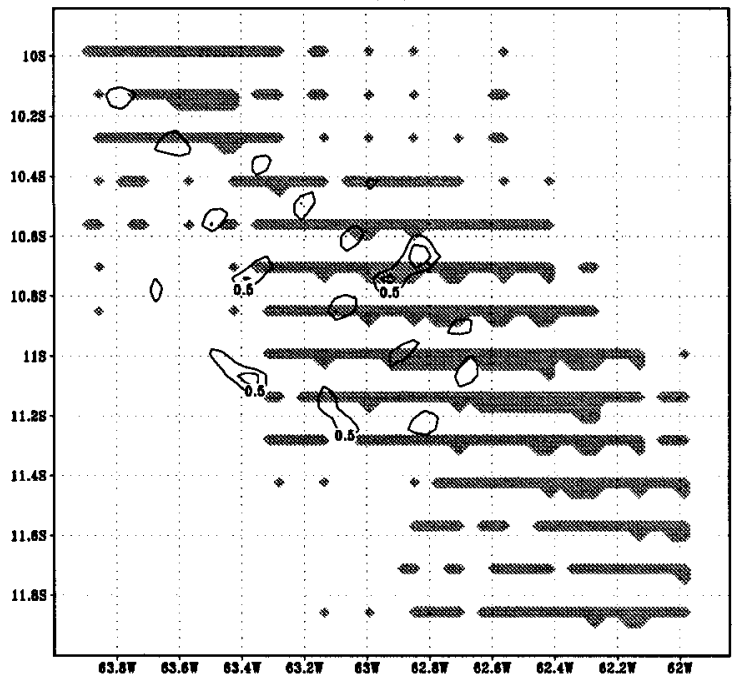

FIG. 20. Same as Fig. 19 but for the deforestation run.

rainfall and clouds around the deforested locations? Were mesoscale circulations responsible for triggering the (shallow and/or deep) moist convection?

There was evidence of mesoscale circulation development as reflected in the mesoscale heat flux. Figure 25 illustrates the heat flux computed using Eq. (A1). The structure of the heat flux below $\sim 750 \mathrm{hPa}$ agrees with that of the mesoscale heat flux in a dry atmosphere described earlier in the paper, hence it could be interpreted safely as an indication of mesoscale circulations. The structure of the heat flux above $\sim 750 \mathrm{hPa}$ in the early afternoon on the first day follows the vertical distribution of clouds up to near the 300-hPa level. We argue that the heat released from condensation associated with moist convection was responsible for the upward transport of heat above the $700-\mathrm{hPa}$ level during the afternoon of the first day, when the mesoscale circulations had triggered not only shallow convection but also deep convection that led to localized rainfall (Fig. 18b). The negative heat flux during the second afternoon indicates that the overall moist convection was stronger in the control run than in the deforestation run, although the resultant clouds were less organized in both runs (Fig. 24). The strength of the mesoscale circulations at low level on the first day was the greatest in terms of magnitude and depth of the corresponding heat flux below $800 \mathrm{hPa}$. The mesoscale circulations during the second day were the weakest, as indicated by the small values of mesoscale heat 
(a)

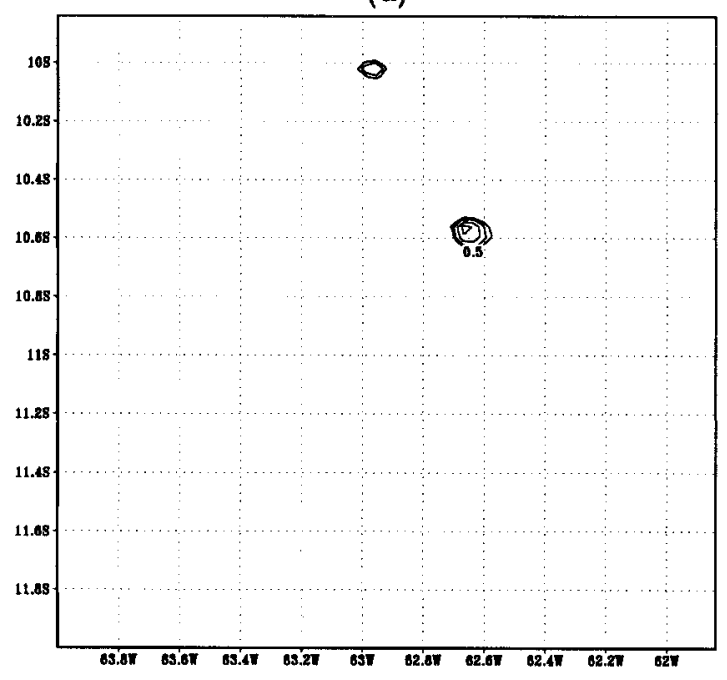

(b)

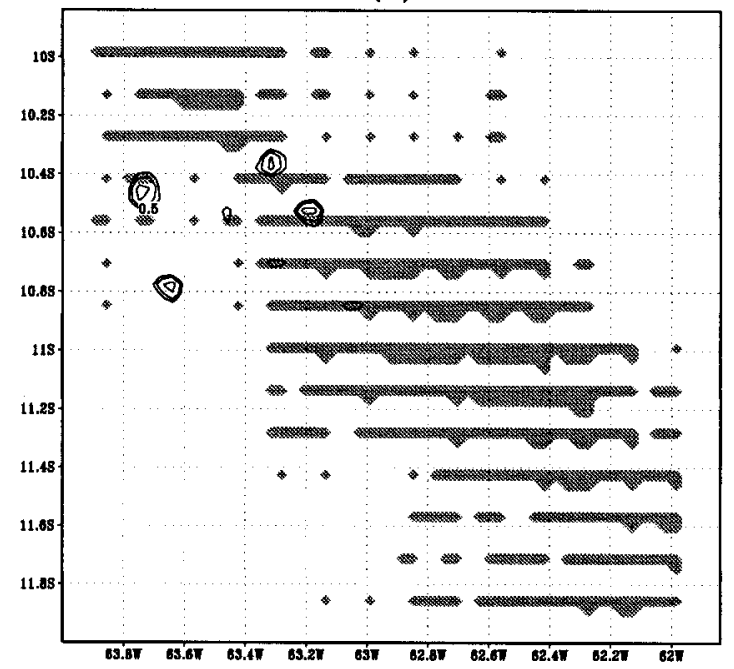

FIG. 21. High cumulus clouds (integrated cloud water up from the 600-hPa level) at $1700 \mathrm{LT}$ on $1 \mathrm{Jul}$ 1990. (a) Control run and (b) deforestation run. Dry-season simulation.

flux. This pattern of mesoscale circulation development was consistent with the conditions of synoptic wind, which was strongest during the second day and weakest during the first day, because the synoptic wind tends to inhibit the development of mesoscale circulations (e.g., Wang et al. 1996).

The analysis of convection patterns, rain locations, cloud depths, and behavior of (mesoscale) heat flux suggests that the organized mesoscale circulations caused by the deforestation play a role in triggering convection that leads to enhancement of afternoon cloudiness and local rainfall. The synoptic forcing during the first day of the dry-season simulation was somewhat similar to that during the break period, with a weakened synoptic wind so that mesoscale circulations developed to a significant level to trigger moist convection. The model shows that the mesoscale circulations could trigger deep convection that contributes local rainfall. During the second day of the dry-season simulation, the synoptic forcing was relatively strong, as in a rainy season, so that mesoscale circulations did not fully develop to provide a triggering mechanism for convection.

\section{Conclusions}

A number of numerical simulations using the MM5 numerical model have been carried out to investigate the role of land surface heterogeneity in shaping the rainfall and cloudiness patterns in Rondônia, Amazonia. Observed land cover data were used to represent the actual scales in the land surface heterogeneity. The atmospheric responses to the contrasting land surface conditions in three climatic regimes in Rondônia, namely, the wet season, the dry season, and the transition season (break period), were simulated to evaluate the relative importance of synoptic forcing and mesoscale forcing in the formation of rainfall and cloudiness. Several conclusions may be drawn based on the simulation results.

- The impact of small-scale $\left(\sim 10^{1} \mathrm{~km}\right)$ deforestation on local convection and rainfall depends on the relative strength of synoptic-scale, mesoscale, and local forcings.

- Mesoscale circulations could develop when the synoptic forcing is relatively weak. Under the condition of less-stable atmosphere and weak synoptic wind, mesoscale circulations could trigger moist convection, leading to shallow nonprecipitating cumulus clouds and, sometimes, high precipitating cumulus clouds over the deforested surface.

- The numerical model predicted that the deforestation in Rondônia had no effect on the distributions of rainfall and cloudiness during the rainy season when mesoscale circulations were inhibited by a relatively strong synoptic forcing. During the break period, mesoscale circulations caused by the deforestation in Rondônia may trigger convection, leading to an enhancement of shallow cumulus clouds under the condition of weakened synoptic wind. During the dry season, the mesoscale circulations over the deforested region not only caused enhancement of shallow clouds but also triggered deep convection that contributes local rainfall, although the signature of land cover in the rainfall was not as strong as that in the enhanced shallow clouds.

These findings certainly are limited by the capability of the current generation of MM5 and the available computing resources. In particular, the representation of land surface processes was somewhat oversimplified such as, for example, the lack of dynamics of soil moisture in spite of the reasonably simulated 
(a)

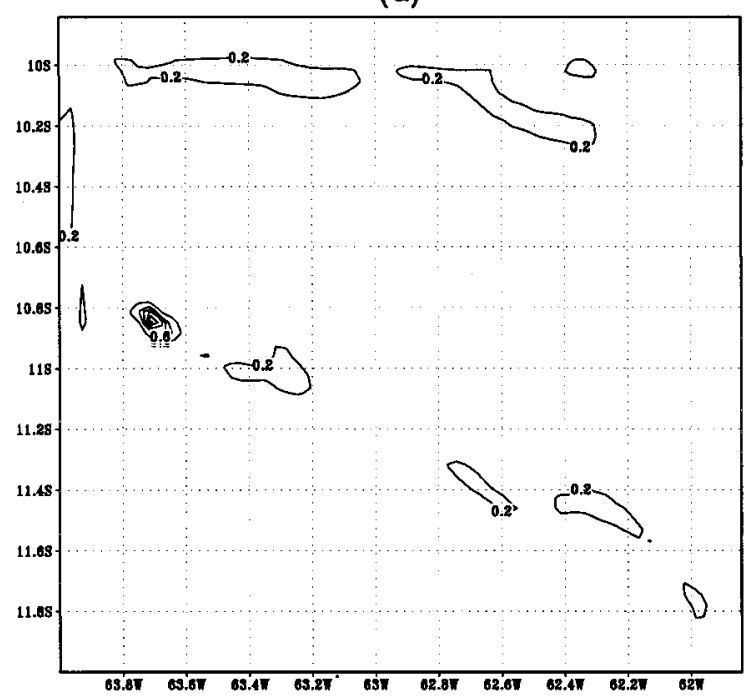

(c)

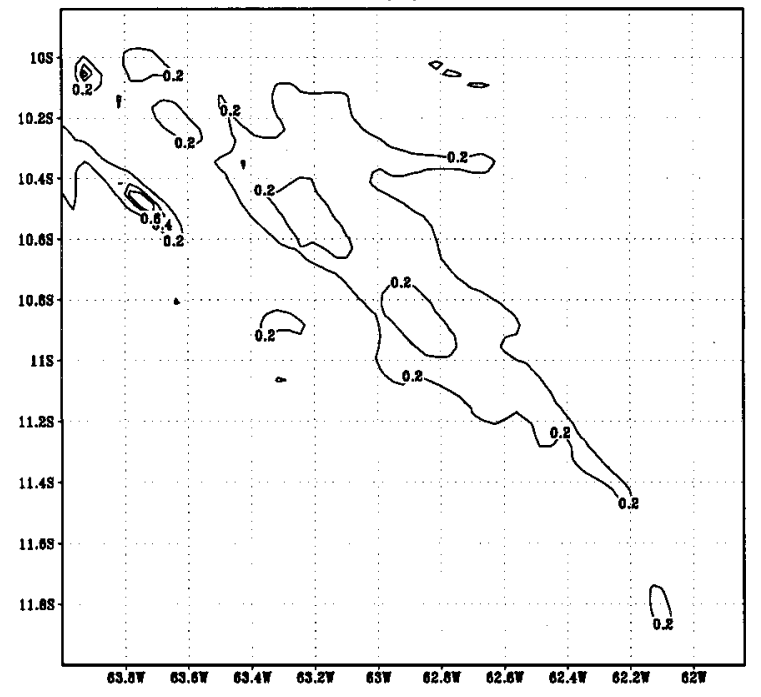

(b)

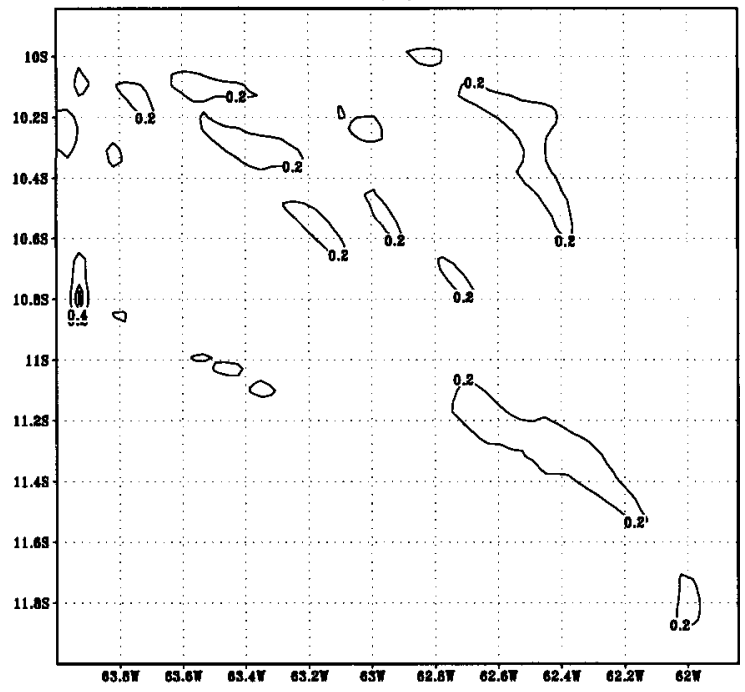

(d)

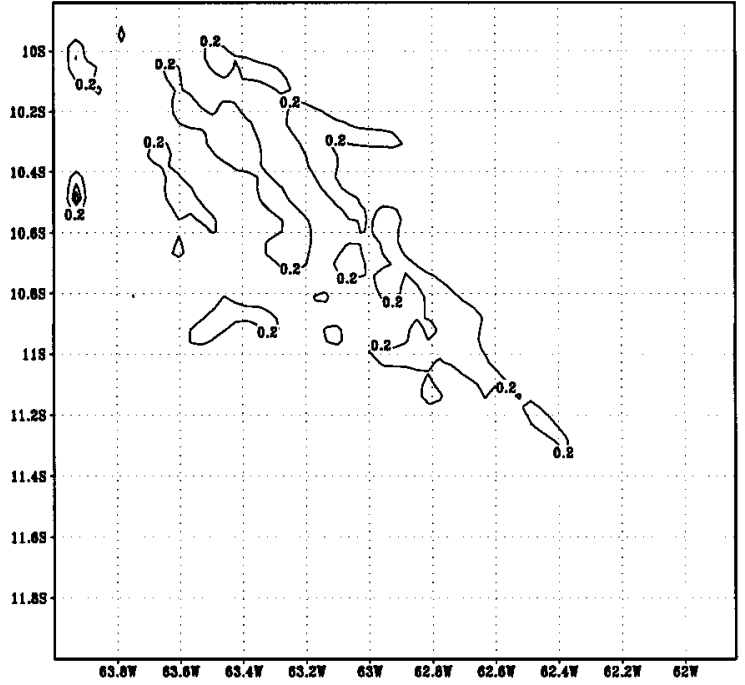

FIG. 22. Same as Fig. 19 but for 3 Jul 1990 (third day of simulation). (a) 1500, (b) 1600, (c) 1700, and (d) 1800 LT.

turbulent heat fluxes and ground temperature. The use of 4-km grid size may also limit the ability to resolve the structures of rainfall and cloudiness. Nevertheless, we are encouraged by the fact that these findings are consistent with the observational studies for both tropical and midlatitude regions (Cutrim et al. 1995; Rabin et al. 1990). Observational studies on the relation between the variable land cover and the change in local rainfall have not been published, to our knowledge. We expect that the observations from the Tropical Rainfall Measurement Mission (TRMM) will help to provide useful information in validating the findings of this research.
Acknowledgments. This work was funded by the NASA TRMM project under Grant NAG5-3726. We gratefully acknowledgment the support from the NCAR SCD, who provided computing resources. We thank the NCAR/MM5 group for their assistance in running the workstation version of the numerical model. We especially thank Dr. Wei Wang for her answers to our many questions about MM5 throughout this project.

\section{APPENDIX}

\section{Definition of Mesoscale Heat Flux}

Mesoscale heat flux $H_{m}$ may be defined in the following way, suggested by Avissar and Chen (1993) as 
(a)

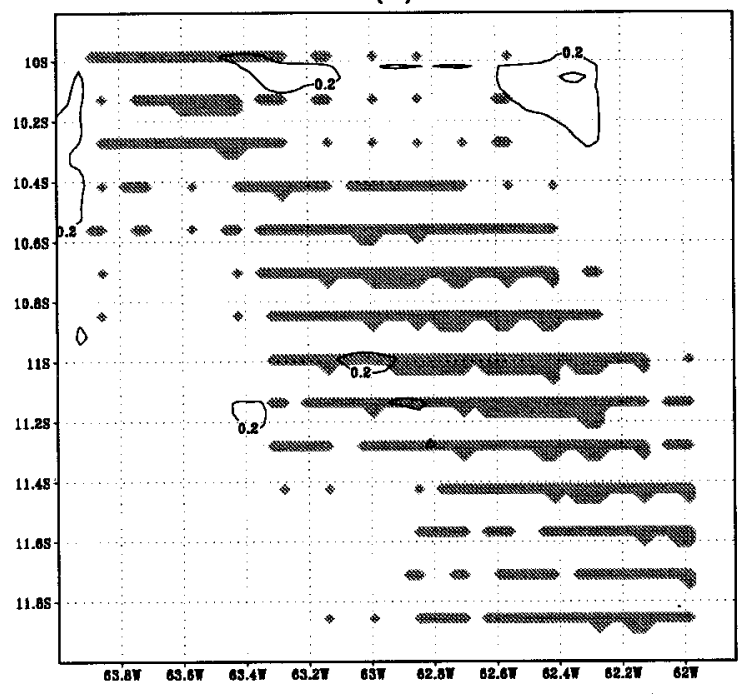

(c)

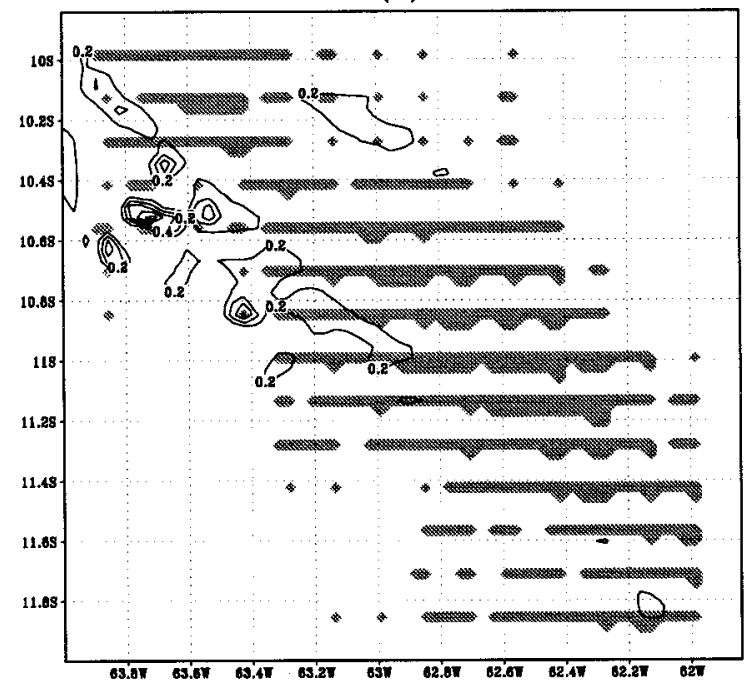

(b)

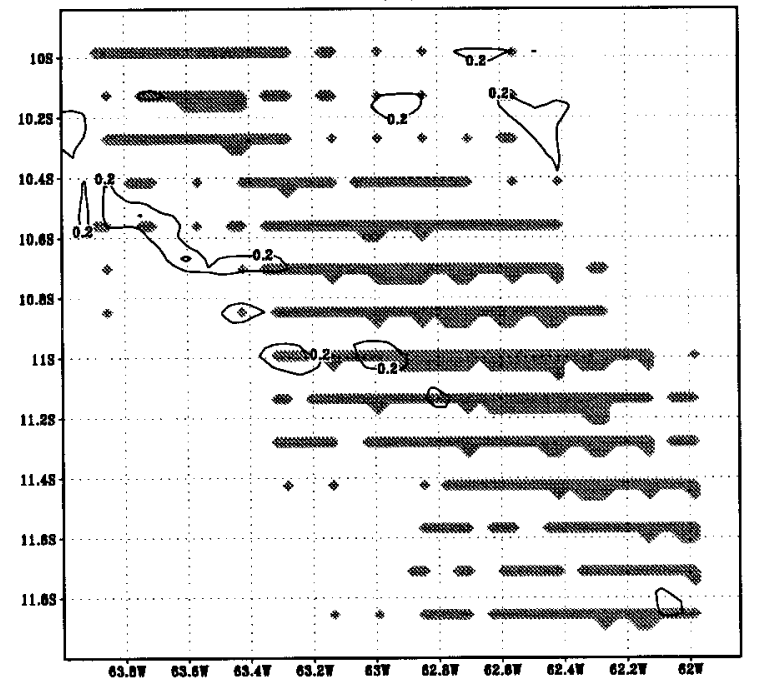

(d)

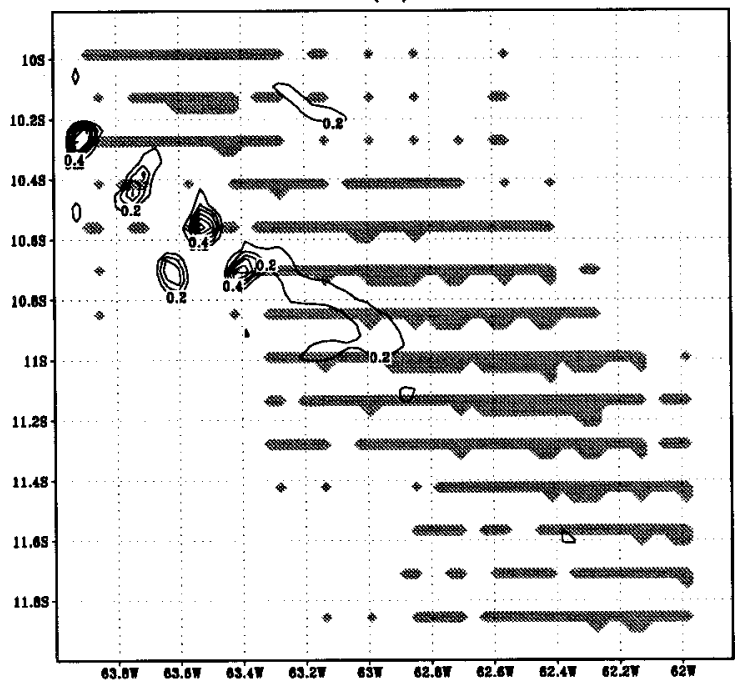

FIG. 23. Same as Fig. 22 but for the deforestation run.

$$
H_{m}=\overline{w^{\prime} \theta^{\prime}},
$$

where $w$ is vertical wind, and $\theta$ is potential temperature associated with the mesoscale circulations induced by the heterogeneous land surface, the overbar represents (horizontal) domain average, and the primed term represents the perturbation around the corresponding domain average.

The state variables $w$ and $\theta$ that describe the mesoscale circulations obviously have the following properties (e.g., Wang et al. 1996):

$$
\begin{aligned}
& \bar{w}=0 \quad \text { and } \\
& \bar{\theta}=\theta_{0}(z),
\end{aligned}
$$

where $\theta_{0}(z)$ is determined by the large-scale atmospheric stability condition and is invariant horizontally.

When using the output from a numerical model simulation, the (horizontal) domain means of $w$ and $\theta$ should be computed at all vertical levels. These domain means represent the synoptic flow conditions. The primed terms can be obtained by subtracting the model output of $w$ and $\theta$ from the corresponding domain means. The mesoscale heat flux from deforestation can be expressed as the difference between the heat flux computed using Eq. (A1) from a deforestation run and that from the corresponding control run. In practice, vertical velocity and potential temperature associated with synoptic flow may vary over the simulation do- 
(a)

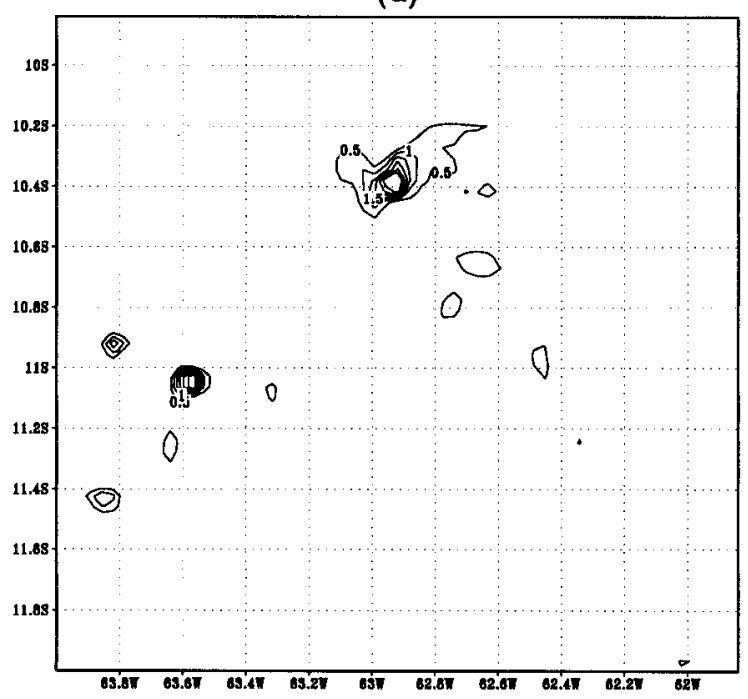

(b)

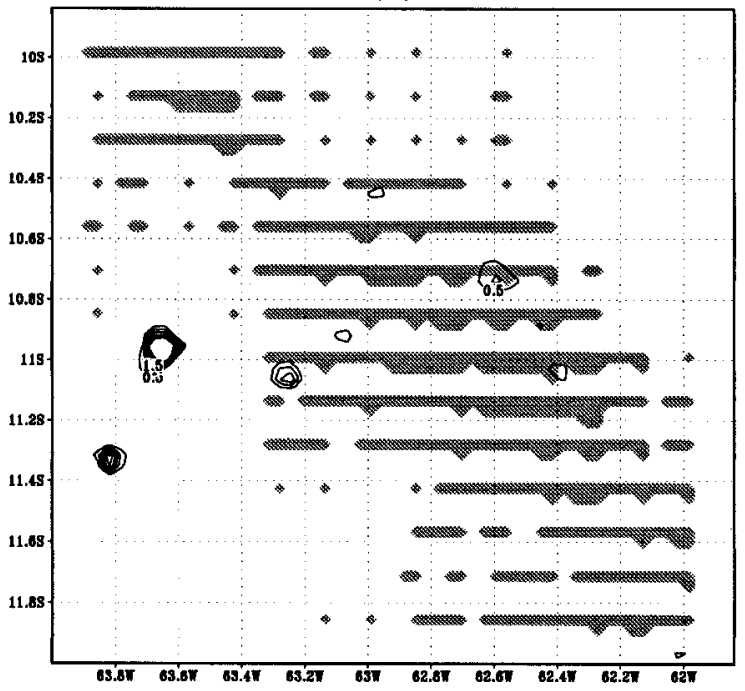

FIG. 24. Cloudiness at 1400 LT 2 Jul 1990 local time (second day of simulation). (a) Control run and (b) deforestation run. Dry-season simulation.

main. When this variation happens, the mesoscale heat flux calculated using Eq. (A1) may involve some errors.

\section{REFERENCES}

Avissar, R., and R. A. Pielke, 1989: A parameterization of heterogeneous land surfaces for atmospheric numerical models and its impact on regional meteorology. Mon. Wea. Rev., 117, 2113 2136.

_, and F. Chen, 1993: Development and analysis of prognostic equations for mesoscale kinetic energy and mesoscale (subgrid scale) fluxes for large-scale atmospheric models. J. Atmos. Sci., 50, 3751-3774.

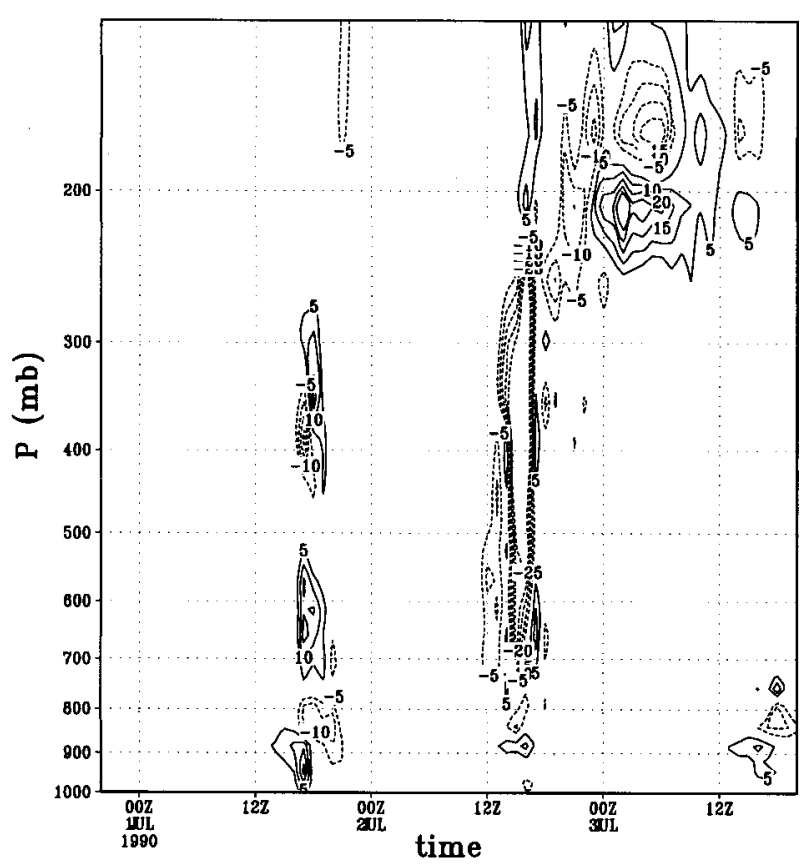

FIG. 25. Mesoscale heat flux $\left(\mathrm{W} \mathrm{m}^{-2}\right)$ caused by the variable land cover. Dry-season simulation.

Cutrim, E., S. W. Martin, and R. Rabin, 1995: Enhancement of cumulus clouds over deforested lands in Amazonia. Bull. Amer. Meteor. Soc., 76, 1801-1805.

Dalu, G. A., and R. A. Pielke, 1989: An analytical study of the sea breeze. J. Atmos. Sci., 46, 1815-1825.

$\longrightarrow$, and — 1993: Vertical heat fluxes generated by mesoscale atmospheric flow induced by thermal inhomogeneities in the PBL. J. Atmos. Sci., 50, 919-926.

— — - R. Avissar, M. Baldi, and A. Guerrini, 1991: Linear impact of thermal inhomogeneities on mesoscale atmospheric flow with zero synoptic wind. Ann. Geophys., 9, 641-647.

Dickinson, R. E., and A. Henderson-Sellers, 1988: Modeling tropical deforestation: A study of GCM land surface parameterizations. Quart. J. Roy. Meteor. Soc., 114, 439-462.

- , and P. Kennedy, 1992: Impacts on regional climate of Amazon deforestation. Geophys. Res. Lett., 19, 1947-1950.

Eltahir, E. A. B., 1996: Role of vegetation in sustaining large-scale atmospheric circulations in the Tropics. J. Geophys. Res., 101, 4255-4268.

— estation in the Amazon basin. Adv. Water Resour., 17, 101-115.

Grell, G. A., J. Dudhia, and D. R. Stauffer, 1994: A description of the Fifth-Generation Penn State/NCAR Mesoscale Model (MM5). NCAR Tech. Note NCAR/TN-398+STR, 122 pp.

Lean, J., and D. A. Warrilow, 1989: Simulation of the regional climate impact of Amazon deforestation. Nature, 342, 411-413.

Lynn, B. H., D. Rind, and R. Avissar, 1995: The importance of mesoscale circulations generated by subgrid-scale landscape heterogeneities in general circulation models. J. Climate, 8, 191205.

Nobre, C. A., P. J. Sellers, and J. Shukla, 1991: Amazonia deforestation and regional climate change. J. Climate, 4, 957-988.

Pielke, R. A., 1974: A three-dimensional numerical model of sea breeze over south Florida. Mon. Wea. Rev., 102, 115-139.

Rabin, R. M., S. Stadler, P. Wetzel, D. J. Stensrud, and M. Gregory, 1990: Observed effects of landscape variability on convective clouds. Bull. Amer. Meteor. Soc., 71, 272-280. 
Rotunno, R., 1983: On the linear theory of the land and sea breeze. J. Atmos. Sci., 40, 1999-2009.

Segal, M., W. E. Schreiber, G. Kallos, J. R. Garratt, A. Rodi, J. Weaver, and R. A. Pielke, 1989: The impact of crop areas in Northern Colorado on midsummer mesoscale thermal circulations. Mon. Wea. Rev., 117, 809-825.

Skole, D., and C. Tucker, 1993: Tropical deforestation and habitat fragmentation in the Amazon: Satellite data from 1978 to 1988. Science, 260, 1905-1910.
Wang, J., R. Bras, and E. A. B. Eltahir, 1996: A stochastic linear theory of mesoscale circulation induced by the thermal heterogeneity of the land surface. J. Atmos. Sci., 53, 3349-3366.

— E. A. B. Eltahir, and R. L. Bras, 1998: Numerical simulation of mesoscale circulation induced by the thermal heterogeneity of land surface. J. Atmos. Sci., 55, 447-464.

Weisman, L., W. C. Skarmarock, and J. B. Klemp, 1997: Resolution dependence of explicitly modeled convective systems. Mon. Wea. Rev., 125, 527-548. 